\title{
Adaptive Liquid Crystal Windows
}

\section{FINAL TECHNICAL REPORT}

DOE Award Number: $\quad$ DE-EE000236

Award Recipient: $\quad$ AlphaMicron, Inc.

1950 State Route 59, Suite 100, Kent, OH 44240-4112

Project Title: $\quad$ Adaptive Liquid Crystal Windows

Principal Investigator: $\quad$ Bahman Taheri, Ph.D. (taheri@alphamicron.com)

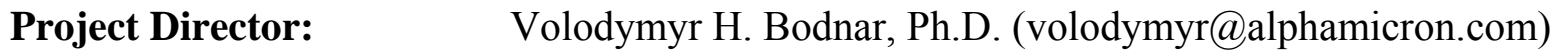

Date of Report: $\quad$ January 31, 2011

Reporting Period: $\quad$ November 1, 2009 - December 31, 2011

Total Number of Pages: 50

Distribution Notice: This report is approved for public release; distribution unlimited. 


\section{DISCLAIMER}

This report was prepared as an account of work sponsored by an agency of the United States Government. Neither the United States Government nor any agency thereof, nor any of their employees, makes any warranty, express or implied, or assumes any legal liability or responsibility for the accuracy, completeness, or usefulness of any information, apparatus, product, or process disclosed, or represents that its use would not infringe privately owned rights. Reference herein to any specific commercial product, process, or service by trade name, trademark, manufacturer, or otherwise does not necessarily constitute or imply its endorsement, recommendation, or favoring by the United States Government or any agency thereof. The views and opinions of authors expressed herein do not necessarily state or reflect those of the United States Government or any agency thereof. 


\section{Table of Contents}

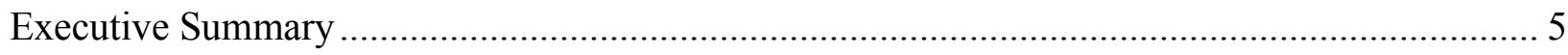

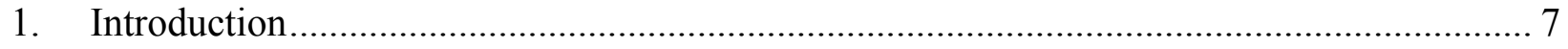

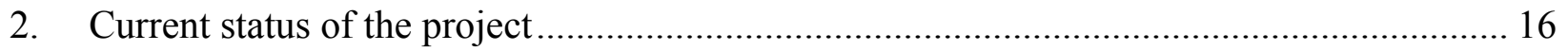

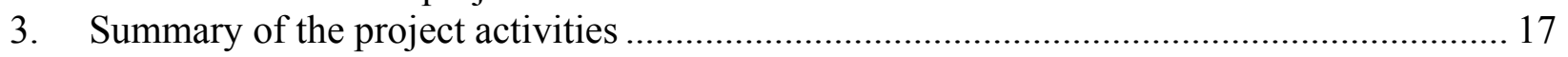

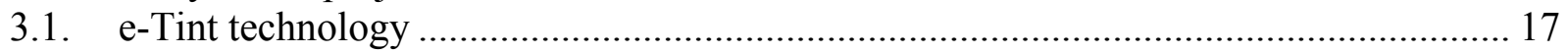

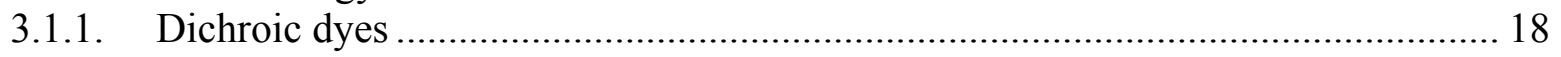

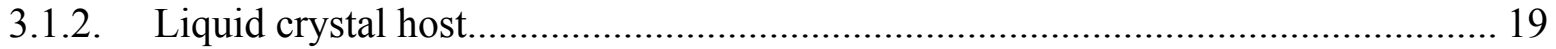

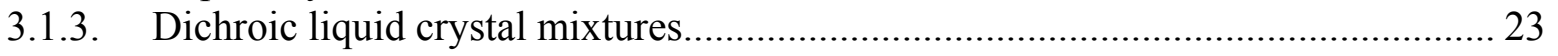

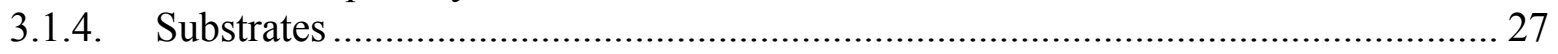

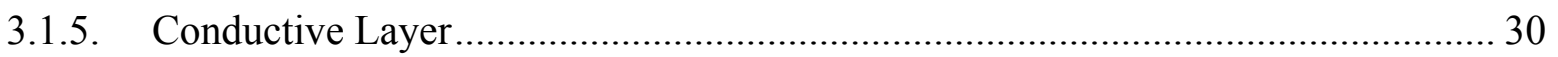

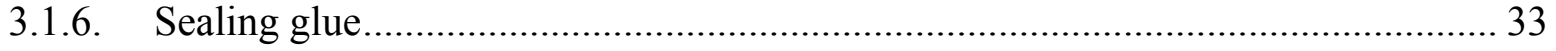

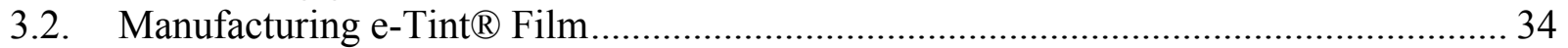

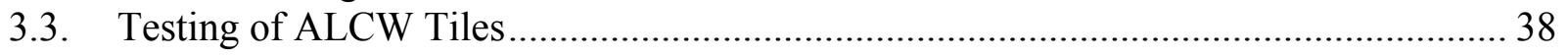

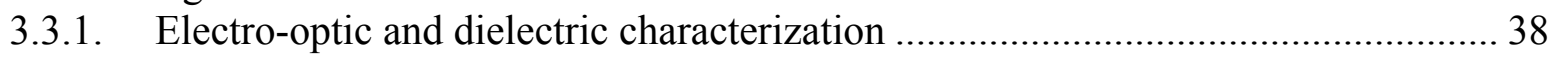

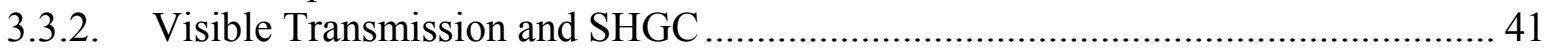

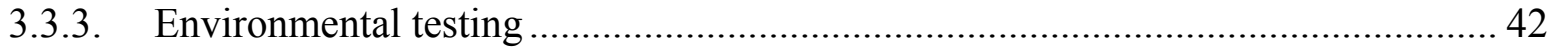

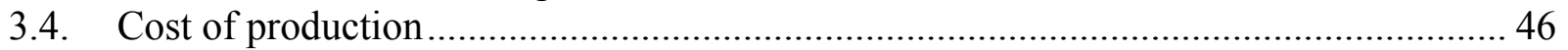

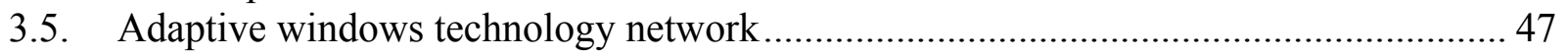

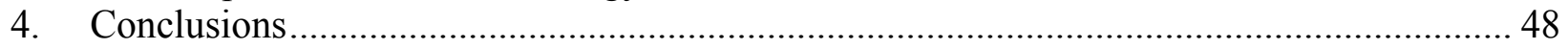

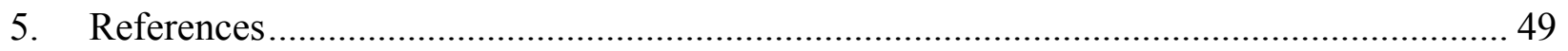




\section{Table of Figures}

Figure 1. Estimated U.S. energy in 2010 by Lawrence Livermore National Laboratory. [1] ........ 8

Figure 2. U.S. Energy Overview, 1949-2010 [2]........................................................ 8

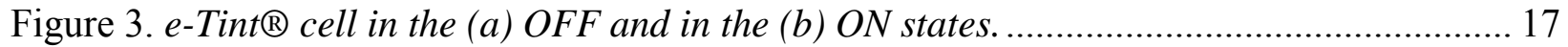

Figure 4. Performance of AMI's dichroic dyes in a variety of LC hosts. ................................... 22

Figure 5. Absorption spectra of selected AMI dyes. Measurements were made with light polarized along the director of aligned LC cells. .................................................................. 23

Figure 6. Simulated transmission curves for ALCW mixtures: (a) 80\% transmission in off-state,

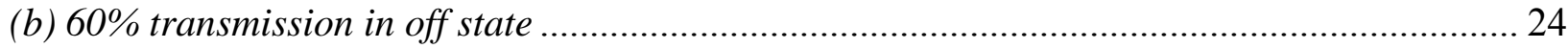

Figure 7. Measured transmission curves of a black e-Tint device.............................................. 26

Figure 8. Typical electro-optic response curve for an e-Tint cell. Blue circles correspond to off-

on state change, red circles, to on-off change. .................................................................... 26

Figure 9. Diagram of an e-Tint ${ }^{\circledR}$ liquid crystal cell in the "voltage-off" or clear state. The guesthost liquid crystal mixture is represented by the rods at the center of the device....................... 27 Figure 10. MiniLabo web coating machine from Yasui Seki, Japan, utilizing MICROGRAVURE

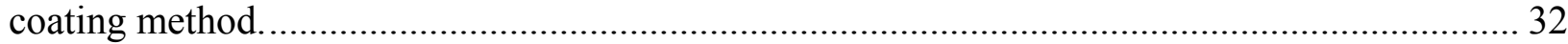

Figure 11. A schematic diagram demonstrating how the MICROGRAVURE ${ }^{\mathrm{TM}}$ application

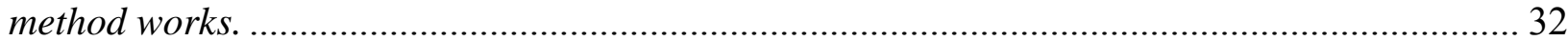

Figure 12. Manufacturing process flow for $e-$ Tint $^{\circledR}$ ALCW technology..................................... 35

Figure 13. A schematic representation of an ALCW cell........................................................... 36

Figure 14. A demo window made with $1 \mathrm{ft} \times 1 \mathrm{ft}$ ALCW film laminated to the glass surface of the bottom panel. The window is driven either with a small battery embedded in the window frame or with a small solar cell mounted on the top portion of the frame......

Figure 15. Current as function of driving AC signal frequency in a $1 \mathrm{ft} \times 1 \mathrm{ft}$ ALCW cell. Applied voltage is fixed for each curve and increases from the bottom curve $(0.1 \mathrm{~V})$ to the top one $(9 \mathrm{~V}) .40$ Figure 16. Impedance and phase of impedance measurements for a $1 \mathrm{ft} \times 1 \mathrm{ft} A L C W$ panel.

Applied voltage is fixed at $6 \mathrm{~V}$.

Figure 17. QUV Accelerated Weathering Tester. ................................................................. 42

Figure 18. Q-SUN Xe-3 Xenon Test Chamber.................................................................... 43

Figure 19. 2in $\times$ 2in test samples (a) before and (b) after 1000 hours of thermo shock testing. . 45 


\section{Table of Tables}

Table 1. Physical properties of liquid crystal hosts under investigation.................................. 21

Table 2. Absorptive characteristics of selected dichroic dyes in AMLC-0010 ......................... 22

Table 3. DCNM-0310, DLC mixture composition (dye components only)............................... 25

Table 4. Comparison of physical and chemical characteristics for plastic films........................ 28

Table 5. ORGACON conductive coating formulations from Agfa-Gevaert N.V ...................... 30

Table 6. UV curable sealing glues ...................................................................................... 33

Table 7.Results of the UV stability testing of ALCWtest cells with UV blocks .......................... 44

Table 8. Current cost of materials used in production of $1 \mathrm{ft} \times 1 \mathrm{ft} A L C W$ test cells ................... 46 
ADAPTIVE LIQUID CRYSTAL WINDOWS: FINAL TECHNICAL REPORT

\section{Executive Summary}

Energy consumption by private and commercial sectors in the U.S. has steadily grown over the last decade. The uncertainty in future availability of imported oil, on which the energy consumption relies strongly, resulted in a dramatic increase in the cost of energy. About $20 \%$ of this consumption are used to heat and cool houses and commercial buildings. To reduce dependence on the foreign oil and cut down emission of greenhouse gases, it is necessary to eliminate losses and reduce total energy consumption by buildings.

To achieve this goal it is necessary to redefine the role of the conventional windows. At a minimum, windows should stop being a source for energy loss. Ideally, windows should become a source of energy, providing net gain to reduce energy used to heat and cool homes. It is possible to have a net energy gain from a window if its light transmission can be dynamically altered, ideally electronically without the need of operator assistance, providing optimal control of the solar gain that varies with season and climate in the U.S. In addition, the window must not require power from the building for operation. Resolution of this problem is a societal challenge and of national interest and will have a broad global impact. For this purpose, the year-round, allclimate window solution to provide an electronically variable solar heat gain coefficient (SHGC) with a wide dynamic range is needed.

AlphaMicron, Inc. (AMI) developed and manufactured $1 \mathrm{ft} \times 1 \mathrm{ft}$ prototype panels for the world's first auto-adjusting Adaptive Liquid Crystal Windows (ALCWs) that can operate from sunlight without the need for external power source and demonstrate an electronically adjustable SHGC. This novel windows are based on AlphaMicron's patented e-Tint ${ }^{\circledR}$ technology, a guesthost liquid crystal system implemented on flexible, optically clear plastic films. This technology 
is suitable both for OEM and aftermarket (retro-fitting) lamination to new and existing windows. Low level of power consumption by ALCWs allows for on-board power electronics for automatic matching of transmission through windows to varying climate conditions without drawing the power from the power grid. ALCWs are capable of transmitting more sunlight in winters to assist in heating and less sunlight in summers to minimize overheating. As such, they can change the window from being a source of energy loss to a source of energy gain. In addition, the scalable AMI's roll-to-roll process, proved by making $1 \mathrm{ft} \times 1 \mathrm{ftALCW}$ prototype panels, allows for cost-effective production of large-scale window panels along with capability to change easily their color and shape.

In addition to architectural glazing in houses and commercial buildings, ALCWs can be used in other applications where control of sunlight is needed, such as green houses, used by commercial produce growers and botanical gardens, cars, aircrafts, etc. 
ADAPTIVE LIQUID CRYSTAL WINDOWS: FINAL TECHNICAL REPORT

\section{Introduction}

In 2010, America's energy consumption was 98 quadrillion BTU’s (quads) (Figure 1); $30 \%$ of this total was imported (Figure 1). This dependence on imported energy coupled with the uncertainty in the extent of future availability in imported petroleum has resulted in a dramatic increase in the cost of energy over the several past years. In turn, that has placed a considerable strain on the economy and has prompted calls for energy independence. Approximately 20 quads of energy consumption in 2010 were used for warming our private houses and commercial buildings during cool weather and cooling them during warm weather $[2,3]$. Of this, over 4 quads are lost through the building's windows [3]. This is despite the current designs in low emission windows. Therefore energy equal to the nation's entire Strategic Petroleum Reserve is lost, annually, through our windows [2]. To achieve energy independence, is necessary to eliminate losses and reduce total energy consumption by buildings.

The rise in cost of heating and the public awareness of greenhouse gas emissions has resulted in demand for Zero-Energy Buildings [3] wherein all energy used is from renewable sources. In these buildings, windows should cease to be a source for energy loss and should, instead, be a source of energy gain. This can be achieved if two conditions are met. First, the window must have electronically controllable tint so that it can automatically adjust light transmission depending on ambient climate conditions (allow more light to enter in winter to heat the house and less light to enter in summer to stop solar overheating). Second, the window must generate power to perform this regulating function self-sufficiently. 


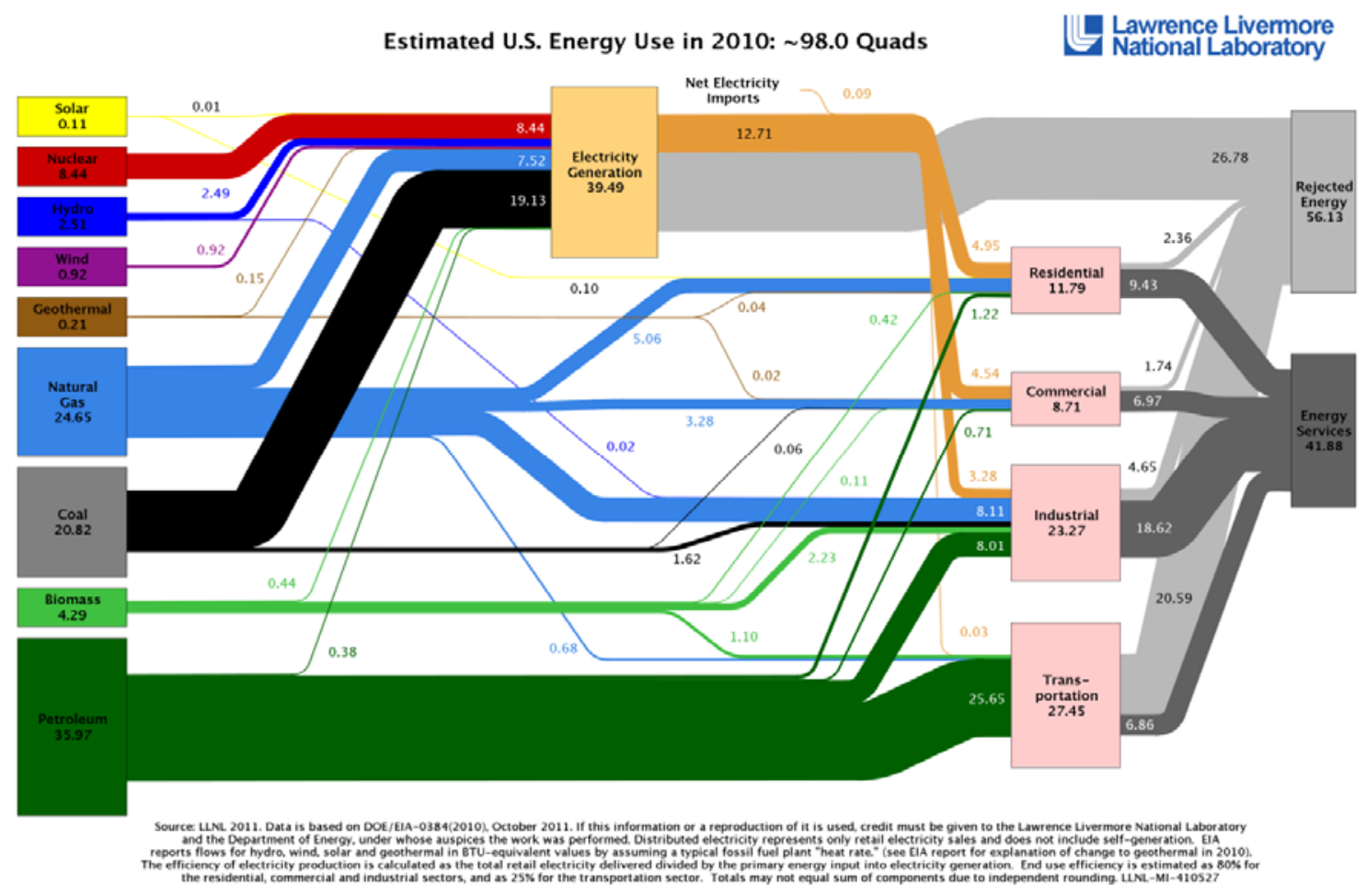

Figure 1. Estimated U.S. energy in 2010 by Lawrence Livermore National Laboratory. [1]

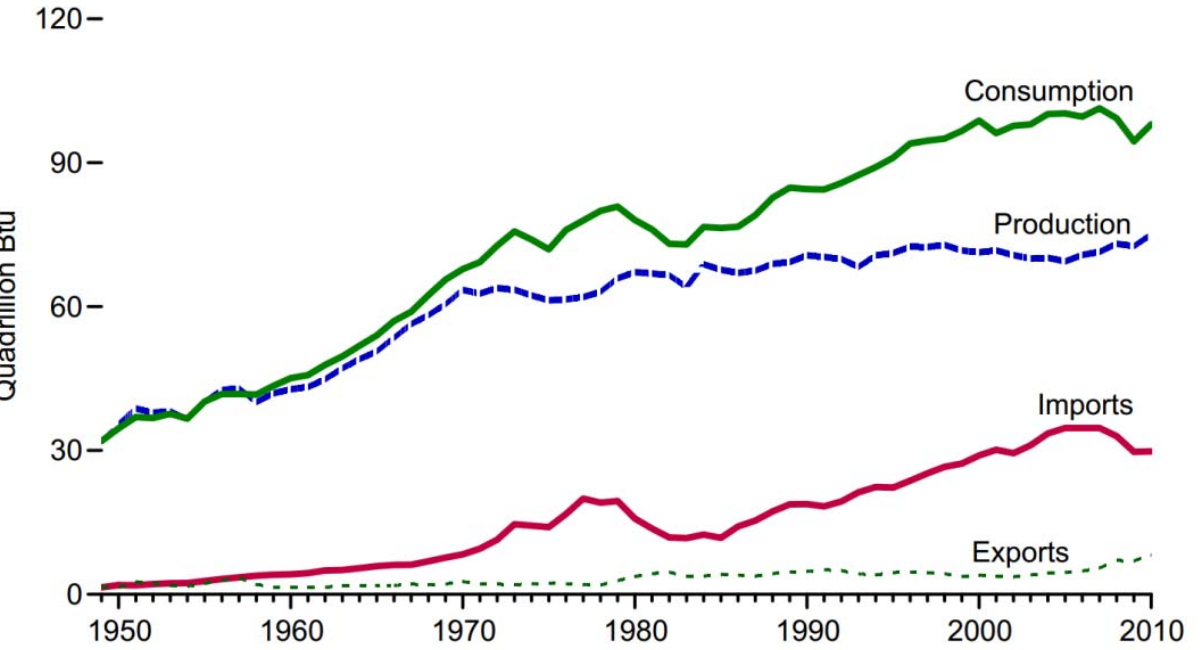

Figure 2. U.S. Energy Overview, 1949-2010 [2].

Since the 1973 energy crisis, technologies that reduce losses from windows have mushroomed. Windows today employ multiple glazing, high-tech materials like aerogel between 
the glazing, and low-emittance (low-E) coatings to minimize heat loss. There are also coatings that are much more reflective of infrared light than visible light. However, even windows that employ all these advances have losses of $\sim 0.4 \mathrm{Btu} / \mathrm{hr} \mathrm{ft}^{2} \mathrm{~F}$ (U-factor) [3]. Therefore, currently, all windows remain a source for energy loss. In addition, the static nature of the technologies suggests that the window's performance is not optimum for all climate and weather conditions and have to be supplemented with costly fixtures such as shades and blinds. As such the windows are not utilized in the most beneficial manner.

To achieve the goal of a Zero-Energy Building, it is necessary to redefine the role of the conventional windows. At a minimum, windows should cease to be a source for energy loss. In fact, ideally, windows should be a source of energy, providing net gain to reduce the 10 quads of energy used to heat and cool homes. It is possible to have a net energy gain from a window if its light transmission can be dynamically altered depending on ambient climate [3]. For example, a decrease in the transmission of sunlight in the summer can serve to stop the solar heat-loading of buildings and reduce the energy consumption during cooling. However, the same window must allow more sunlight transmission in the winter to reduce the load on heating systems. For this, there is a need for windows whose light transmission characteristics can be altered - ideally electronically. This alteration must be performed automatically and without the need for operator assistance. In addition, the window must not require power from the building for operation. Solar cells can be used if they do not impinge on the viewing area of the window.

Over the past two decades, efforts to realize Adaptive Windows have led to the establishment of a set of performance requirements for successful implementation of variable transmittance and its commercialization. These criteria are the following:

1. Implementation on flexible plastic film 
ADAPTIVE LIQUID CRYSTAL WINDOWS: FINAL TECHNICAL REPORT

2. Adjustability of light transmission from $70 \%-30 \%$

3. Adaptability to varying climate conditions

4. On-board power system and electronics

5. Retro-fitting capability for use with existing windows

6. Cost effectiveness

7. Lifetime of 5-10 years; preferably 30 years.

8. Large scale production capability.

9. Shape selection capability

10. Color selection capability

11. Good optical clarity

The major challenge in creating Adaptive Window system resides in the development of the technology that can provide automatic, haze-free, light transmission control in an optical clear film without the need for an external power source. The system must be integratable into existing glazing. The entity that overcomes these challenges stands to gain significantly from commercialization. A successful Adaptive Window will create a strong industry with a global impact.

There are currently no commercially viable systems that can perform these functions. A number of technologies have been proposed and their realization attempted for electronically controllable tint. They include electrochromic, polymer dispersed liquid crystals, suspended particles systems, and even an electrically controlled mechanical window shade. However, each has had an intrinsic limitation that has prevented its large scale implementation for commercial and residential window applications. 


\section{ADAPTIVE LIQUID CRYSTAL WINDOWS: FINAL TECHNICAL REPORT}

There have been a number of approaches using a variety of technologies to make Adaptive Windows with variable transmittance for. However, none have had commercial success. Creation of a viable Adaptive Window product for architectural glazing applications requires seamless integration of two technologies: namely, variable transmittance technology with low energy consumption and large area manufacturing.

Of these two the most important component is variable transmittance film which has not been demonstrated commercially for window applications. We, therefore, only focus on competing technologies for that aspect.

Electrochromic (EC) is a broad term used for technologies where the transmission of the window is electrically controlled via reversible injection of charge [4]. An adaptive window using this technology is constructed by making a sandwich incorporating an electrochromic ceramic, a solid-state electrolyte and a transparent ion-storage material. The outer layers of the sandwich are transparent conductive electrodes. When a current is made to flow between the electrodes, ions are driven from the storage layer through the electrolyte into the electrochromic material, changing its color. When the current is reversed, the ions return to the storage layer, depleting the electrochromic material so that it becomes transparent again. These products are used in small area applications such as rearview mirrors for automotive applications. Their transmittance ranges from around $10 \%$ in their darkened state to $70 \%$ in their transparent state. They require current to switch states.

Electrochromics suffer from some intrinsic drawbacks which impede their widespread implementation for adaptive windows in architectural applications. One is the "irising" effect caused by charge transfer difference depending on the distance from the electrical connection that makes making large EC windows difficult. To avoid "irising" some expensive techniques to 
reduce this non-uniformity were proposed, but were abandoned due to their expensive nature. Furthermore, high quality requirements to the conductive layer prohibit implementation on flexible plastic substrates. In addition, the process of defect accumulation limits the ion current with time, shortens the device lifetime, and reduces its performance. Further, the chemical nature of the technology makes it extremely susceptible to environmental conditions such as temperature and humidity.

Suspended Particle Device (SPD) has been proposed for smart window applications by Research Frontiers [5]. They are fabricated by suspending anisotropic particles containing dye in an emulsion between transparent conducting electrodes. When an electric field is applied, the particles line up in such a way to reduce light absorption. In the absence of a field, Brownian motion in the emulsion randomizes the orientation of the particles, therefore increasing absorption and scattering. This is similar in spirit to the way the first $\mathrm{H}$-sheet polarizer was formed by mechanically aligning dye containing needle crystals in a plastic sheet. SPD switches within a few seconds.

SPD windows have not been successful in either window or eyewear applications for a number of reasons. The suspended particles do not self-maintain their position and orientation, the system is subject to thermodynamic fluctuations and ceases to function properly over a relatively short time. This is impractical for most applications, especially windows, since they are expected to last several years. In addition, particles degrade due to UV exposure and the technology consumes too much power. One manufacturer estimates power consumption of $0.6 \mathrm{~W}$ per square foot $\left(\sim 650 \mathrm{~mW} / \mathrm{cm}^{2}\right)$ in the clear state. In addition to their technical issues, the energy appetite of SPD windows erases almost any energy savings they might produce. Therefore, SPD has not been commercialized in many sectors. 
There are a few technologies for coating windows where the color changes in response to temperature. Sunlight Responsive Thermocromic (SRT) [6] glass from Pleotint LLC becomes cloudy at low temperatures and clear at higher temperatures. Cloud Gel from SunTek Inc. [7] operates in an opposite manner. Although these windows respond to stimuli (temperature) their performance is very far from ideal. To improve the performance, these windows must be actively controlled; that is one must either heat or cool them, consuming energy. This is not an adaptive window technology that can result in appreciable energy savings.

Photochromic technology is familiar in adaptive vision products, such as sunglasses, that automatically darken when exposed to sunlight. Significant research is being conducted for their use in that as well as optical storage industries. The technology is considered to be relatively mature. They have never been used for window application because of the inherent limitations of the technology. In particular, the photochromics are not stable in the long term and are useful only in application where long term exposure is limited. Optical grade photochromics require UV light for activation which results in a conformational change in the dye molecule. However, the change required for operation also creates radicals which can cause self degradation of the dyes. Therefore, their lifetimes are relatively short; about two orders of magnitude below the required lifetime for any glazing. In addition, since they require UV light for operation, they cannot be used for interior window applications since window glass absorbs UV. Placing them on the outside window presents an operational problem since they are extremely temperature sensitive in a manner not consistent with Adaptive Window operation. In particular, under a constant illumination, they become darker in cold weather. Therefore the window will be darker in the winter than in the summer which is the opposite of the desired behavior. 
Liquid crystal (LC) technologies are optimal for light management applications, as they can be uniquely configured to selectively transmit, absorb, or reflect light across the entire visible and NIR spectrum. Liquid crystal based materials and technologies have evolved over the past two decades and have been commercialized in a variety of applications. Broadly, they can be classified into: (i) polarizer systems, (ii) PDLC technologies, and (iii) cholesteric reflectors, and (iv) dichroic guest-host materials.

Polarizer based systems are most commonly used in display applications. They provide excellent absorption and multiplexing capability. However, the clear state transmission is limited to $15-20 \%$. Also, the polarizer based nature of the technology limits its use with plastic substrates. This characteristic significantly limits use of such systems for adaptive window applications.

Polymer dispersed liquid crystals (PDLC) [8] and NCAP [9] are similar technologies that held a lot of promise for adaptive windows, and were commercially available (Viracon and Marvin Windows) for some time. PDLC's are composed of microscopic liquid crystal droplets encapsulated in a polymer matrix and responsive to the applied electric field. Applying an electric field across this layer aligns the optic axis of the liquid crystal and makes the film transparent in the normal direction if the refractive indices of the polymer and the liquid crystal are appropriately matched. When the electric field is removed, the optic axis of the liquid crystal reverts to its original state and the droplets strongly scatter light. PDLC windows switch much more rapidly than EC. They rely on the electric field rather than charge transfer, so the switching is uniform across large areas. They are amenable to large-scale production because they can be implemented on large areas, flexible plastic substrates and do not require assembly of individual thin layers. 
PDLC technology had little success in the market for advanced windows. The product was not sufficiently resistant to the near UV/visible component of sunlight, and, the polymerdroplet matrix continued to change long after manufacturing was completed, changing the optical properties over time. Furthermore, PDLC windows did not save a lot of energy since much of the scattered light was scattered forward rather than reflected. Sunlight did not traverse the window unimpeded, but it traversed it nonetheless. There is not sufficient reduction in overall energy transfer through the window. PDLC in their "clear" state are hazier than is desired for windows, and, the clarity strongly depends on viewing angle. PDLC didn't offer energy savings, required high power for operation and didn't meet the optical or environmental specifications. However, it is still being used in certain applications.

Cholesteric based systems use the ability of highly twisted structures of liquid crystals to reflect light in a selective region of the light spectrum [10]. However, they cannot operate without haze and as such are not usable for window applications.

Dichroic liquid crystal systems, which were utilized to produced the very first liquid crystal displays (LCDs) [11] used in the avionic industry, do not require polarizers, have wide viewing angle and more tolerance for alignment and cell spacing. Although, not suitable for low cost high information content displays, they offer a great potential for application in Adaptive Windows.

Recently, it was shown that Variable Attenuation Liquid Crystal Device (e-Tint $\left.{ }^{\circledR}\right)$ [10] technology on thin flexible film could meet all the requirements for electronically controllable variable transmittance films. The low power required for operation of $e$-Tint ${ }^{\circledR}$ based films means that solar cells technologies can be used to provide enough energy for self-powering without impinging on the viewing area of the window. 
ADAPTIVE LIQUID CRYSTAL WINDOWS: FINAL TECHNICAL REPORT

\section{Current status of the project}

The overall objective of the Adaptive Liquid Crystal Windows (ALCW) program was to perform research required to develop a cost-effective liquid crystalline film for ALCWs, capable of demonstrating an electronically adjustable tint that allows for dynamic SHGC, produce functional $1 \mathrm{ft} \times 1 \mathrm{ft}(30.5 \mathrm{~cm} \times 30.5 \mathrm{~cm})$ film prototypes, and conduct their environmental stability testing. To achieve this, we proposed to combine two systems:

(i) AlphaMicron's e-Tint ${ }^{\circledR}$ technology [10]: This guest-host dichroic system with low energy consumption was developed for Air Force variable transmittance visor applications.

(ii) Roll-to-roll liquid crystal film processing. The complete system must be reduced to a flexible film which can be laminated to existing glazing. This must be done in a rollto-roll manufacturing process to satisfy for shape and size requirements as well as cost reduction.

The other aspects of the ALCW development such as power generation and electrical connections, as well as large area film implementation (more than $1 \mathrm{sq} . \mathrm{ft}$ ), were out of scope of the current research. The work performed in the Project was divided into three parts: (i) adaptation of variable tint technology, (ii) implementation on plastic films, and (iii) environmental stability testing.

As the result of the project activities we completed adaptation of e-Tint technology to the ALCW requirements, we manufactured fully functional $1 \mathrm{ft} \times 1 \mathrm{ft}$ prototype films with electronically switchable tint and SHGC by using AMI's roll-to-roll equipment, and conducted a series of environmental stability tests. 


\section{Summary of the project activities}

\section{1. e-Tint technology}

To realize Adaptive Liquid Crystal Windows (ALCWs), AlphaMicron, Inc. (AMI) has chosen its own dichroic liquid crystal system, Variable Attenuation Liquid Crystal Device technology [10], recently known as $e$-Tint ${ }^{\circledR}$, to achieve variable transmittance through attenuation. $e$-Tint ${ }^{\circledR}$ was developed over the past fifteen years and uses a non-polymer based, high contrast, guest-host mixture consisting of "guest" dichroic dyes in a liquid crystal "host." This mixture is sandwiched between two flexible plastic films coated with transparent electrodes (Figure 3). By applying a voltage to the film assembly, the electro-optic response of the liquid crystal is used to control the transmittance and the tint of the device. The control voltage can be applied automatically, as a result of a sensor detecting changing lighting conditions, or manually, by touching a switch or a dial.

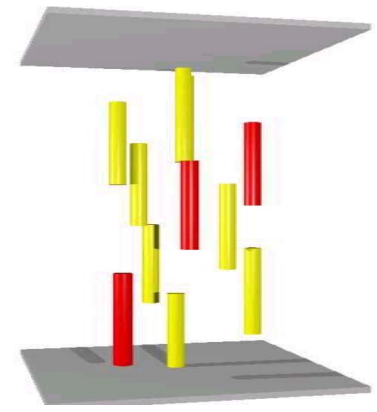

1.

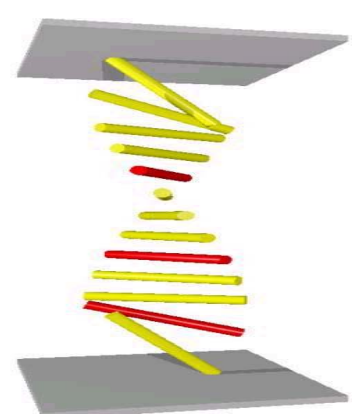

(b)

Figure 3. e-Tint ${ }^{\circledR}$ cell in the (a) OFF and in the (b) ON states.

$e$-Tint $t^{\circledR}$ is based on a modified Gharadjedaghi [12] system initially proposed for display applications. It utilizes a guest-host technology with homeotropic alignment layer, negative LC 
host, and positive guest dye. Figure 3 shows the configuration of the system in the OFF and the ON states.

To achieve light transmission control, high order parameter dichroic dyes are dissolved in the host liquid crystals. The orientation of the dye molecules and the subsequent dipoles are parallel to the host liquid crystal alignment. In this configuration, the un-energized state exhibits the least absorption to ensure fail-to-clear operation essential for window applications. Applying of a voltage reorients the LC and dye which alters the absorption of the light through the material. The direction and degree of reorientation are dictated by the applied voltage as well as the material composition and the surface treatment. Depending on surface treatment and host constituents, the device can be fabricated to exhibit strong polarization dependence and behave as a switchable polarized lens.

The response time of the system is dictated by the viscosity of the host which, for conventional LC materials, is a few milliseconds. The swing in the transmission and hue of the cell are dictated by the absorption properties of the guest dye and its degree of order with respect to the host (order parameter).

\subsubsection{Dichroic dyes}

The performance of guest-host systems strongly depends of the order parameter of the dichroic dyes dissolved in the LC host. Commercially available dichroic dyes used in liquid crystal displays (LCDs) do not have sufficiently high order parameter values required for window applications. Unlike that of a $\operatorname{LCD}[14,15,16]$, the goal of a window is to have a high transmission in the clear state. For daytime usage, this requires dichroic dyes with order 
parameter, S, of greater than 0.82 . In addition, they must survive the sunlight UV tests for glazing applications.

AMI has developed and synthesized a series of high performance dyes, which, combined with selected LC hosts, demonstrate order parameter values of $0.82-0.85$. They also show a stable performance in our UV stability tests. These new materials, whose chemical structure is kept as company's trade secret, are tailored to exhibit absorption across the visible spectrum.

These materials allow the realization of e-Tint ${ }^{\circledR}$ technology with virtually any color tint, and with variable transmittance. By combining multiple dyes, a large hue variety across the visible spectrum can be achieved [13]. This technology can be used to allow the user a single color change for contrast enhancement or a broad tint change for sun protection.

\subsubsection{Liquid crystal host}

We selected a LC host to meet the electro-optic requirements of the ALCW film based on e-Tint ${ }^{\circledR}$ technology. For this purpose we tested several commercial liquid crystal hosts, as well as custom made liquid crystal mixtures. In selection of the LC materials, we looked for the following parameters: large negative dielectric anisotropy, low birefringence, wide operating temperatures, and compatibility with essential additives such as dichroic dyes and chiral additives. The cost of the liquid crystal material is another important factor that could affect the final cost of the device and its viability. At this time it did not play a crucial role for host selection, but was taken into consideration as a parameter. As the result, we considered several liquid crystal mixtures including ones that are commercially available from Merck KGaA and the ones that are custom made with additives synthesized in-house ( 
ADAPTIVE LIQUID CRYSTAL WINDOWS: FINAL TECHNICAL REPORT

Table 1).

Page 20 of 50 
Table 1. Physical properties of liquid crystal hosts under investigation.

\begin{tabular}{|c|c|c|c|c|c|c|c|}
\hline & 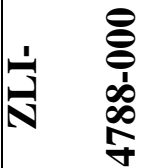 & \begin{tabular}{l}
8 \\
$\stackrel{0}{1}$ \\
$\infty$ \\
$\infty$ \\
\multirow{2}{*}{}
\end{tabular} & 宵 & $\frac{9}{8}$ & 농 & $\begin{array}{l}\mathscr{0} \\
\stackrel{0}{0} \\
\overline{6}\end{array}$ & $\frac{\hat{\sigma}}{0}$ \\
\hline Clearing point $\mathbf{T}_{\mathrm{NI}},{ }^{\circ} \mathrm{C}$ & $83^{\circ} \mathrm{C}$ & $83^{\circ} \mathrm{C}$ & $91.5^{\circ} \mathrm{C}$ & $97^{\circ} \mathrm{C}$ & $>100^{\circ} \mathrm{C}$ & $96^{\circ} \mathrm{C}$ & $95^{\circ} \mathrm{C}$ \\
\hline $\begin{array}{l}\text { Optical anisotropy, } \Delta \mathrm{n} \\
\left(20^{\circ} \mathrm{C}, 589 \mathrm{~nm}\right)\end{array}$ & 0.1647 & 0.164 & 0.0777 & 0.092 & 0.093 & 0.087 & 0.087 \\
\hline Dielectric anisotropy, $\Delta \varepsilon$ & -5.7 & -2.7 & -3.7 & -4.0 & -3.6 & -5.79 & -5.34 \\
\hline
\end{tabular}

The main selection factor for a LC host was the compatibility and performance of the AMI dichroic dyes. For this purpose we tested solubility and dichroic properties of a number of dyes in selected LC hosts. First, we characterized low-concentration dye solutions $(<1 \%)$ in specially designed twin-chamber test cells with rubbed planar alignment. The construction of the test cells ensured the same planar orientation of the tested DLC mixture in the sample chamber, and the reference mixture (pure LC) in the reference chamber. For the absorption characterization of the test mixtures we used a custom-made automated electro-optic setup utilizing on a miniature fiber optics spectrometer from Ocean Optics, Inc. and polarized light. This setup allows determination of the order parameter from the absorption spectra of the dyes in selected liquid crystal hosts. By measuring the absorption of the aligned dichroic LC mixture with light polarized along and normally to the preferred orientation of the LC (director), the order parameter is defined as $\mathrm{S}=(\mathrm{D}-1) /(\mathrm{D}+2)$, where dichroic ration $\mathrm{D}=\mathrm{A}_{\|} / \mathrm{A}_{\perp} \perp_{-}$and $\mathrm{A}_{\|}$and $\mathrm{A} \_\__{\perp}$ are the dye absorbance at the maximum absorption wavelength of the dye $\lambda_{\max }$ measured with light polarized parallel and perpendicular to LC director, respectively. Figure 4 presents the results of order parameter measurements for several dyes in a number of selected LC hosts. 


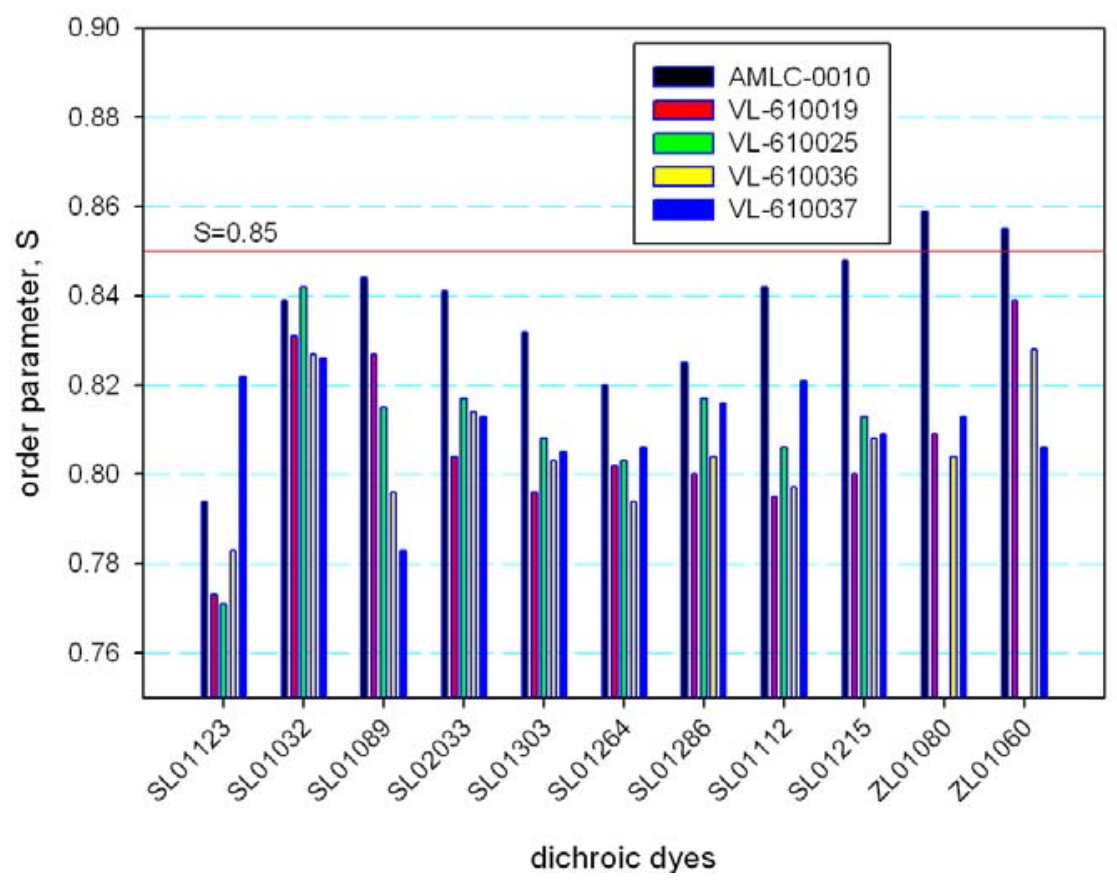

Figure 4. Performance of AMI's dichroic dyes in a variety of LC hosts.

As the result of measurements we selected AMLC-0010 as a host for the ALCW films, as well as limited a number of dyes for further work (Table 2).

Table 2. Absorptive characteristics of selected dichroic dyes in AMLC-0010.

\begin{tabular}{|c|c|c|c|}
\hline Dye Name & Color & $\begin{array}{c}\text { Maximum absorption } \\
\text { wavelength, } \boldsymbol{\lambda}_{\max }[\mathbf{n m}]\end{array}$ & Order parameter, $\mathbf{S}$ \\
\hline AMDD-Y-01123 & yellow & 415 & - \\
\hline AMDD-Y-01032 & yellow & 470 & 0.84 \\
\hline AMDD-Y-01089 & yellow & 472 & 0.84 \\
\hline AMDD-R-01303 & red & 515 & 0.83 \\
\hline AMDD-P-01254 & purple & 555 & 0.82 \\
\hline AMDD-B-01112 & blue & 623 & 0.84 \\
\hline AMDD-B-01215 & blue & 622 & 0.85 \\
\hline
\end{tabular}


AMLC-0010 has a moderate absolute value of $\Delta \varepsilon$, low birefringence. This LC host is very compatible with dichroic dyes which results in highest values of their order parameters. Figure 5 shows the absorption spectra for some of the selected dyes in this LC host.

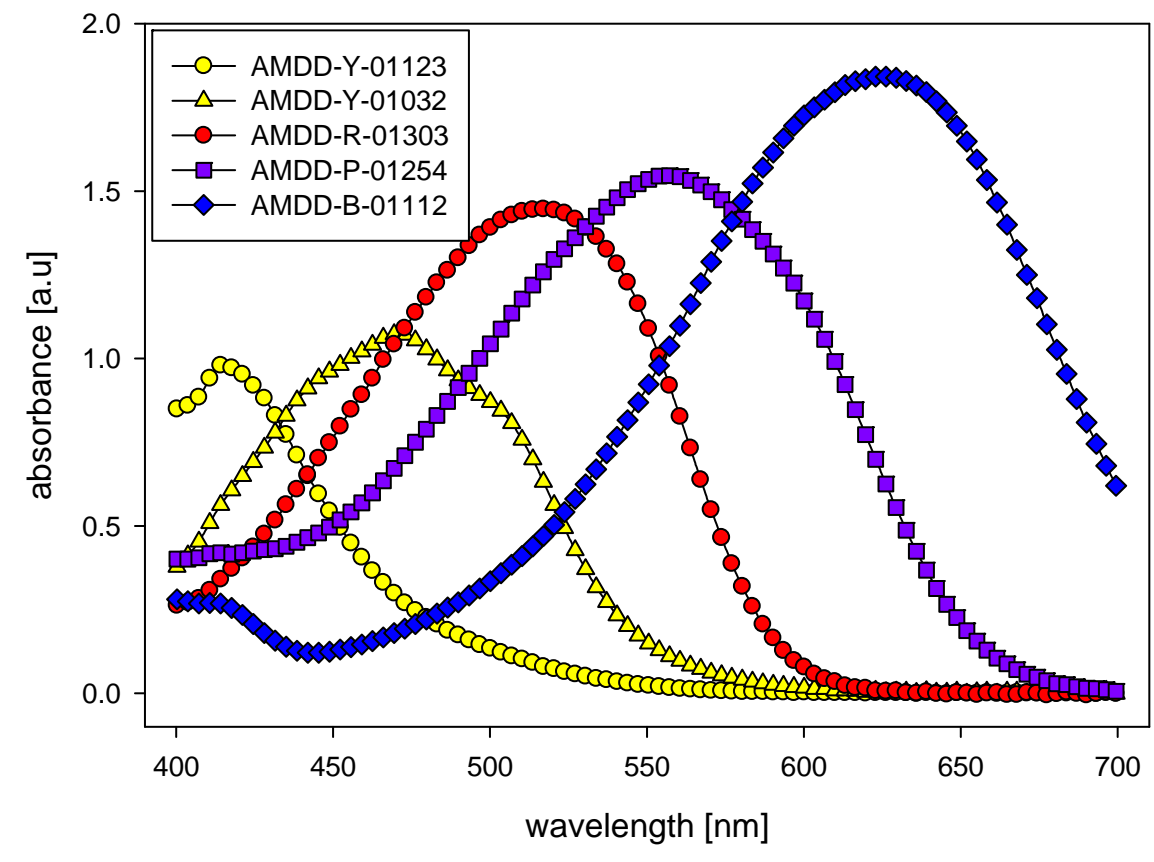

Figure 5. Absorption spectra of selected AMI dyes. Measurements were made with light polarized along the director of aligned LC cells.

\subsubsection{Dichroic liquid crystal mixtures}

Next step is creation of a formulation for the use in manufacturing and testing ALCW prototype panels. Our e-Tint ${ }^{\circledR}$ mixture design objectives for adaptive windows were the following:

- Mixture needs to produce about 0.4 transmittance value swing from 0.7 in the OFF-state to 0.3 in $\mathrm{ON}$-state. 
ADAPTIVE LIQUID CRYSTAL WINDOWS: FINAL TECHNICAL REPORT

- The color of the mixture should be neutral gray. That corresponds to color coordinates close to those of CIE 1931 Standard Illuminant D65: $\mathrm{x}_{2}=0.3127$ and $\mathrm{y}_{2}=03290$.

- The mixture performance should be stable against environmental exposure to meet architectural glazing standards.

- The cost of raw materials should be low (about $\$ 10$ per square foot window or lower).

We formulated and prepared several test dichroic liquid crystal (DLC) mixtures for windows applications by using AMLC-0010 and high order parameter dyes listed in Table 2, whose maximum absorption wavelengths are in a 420 to $630 \mathrm{~nm}$ range. By utilizing spectral data obtained in dye characterization process and AlphaMicron's custom computer simulation program, OptiMix, we simulated several mixtures for $6-\mu \mathrm{m}$ e-Tint ${ }^{\circledR}$ devices for total offtransmission in range from $40 \%$ to $80 \%$ (Figure 6 ).

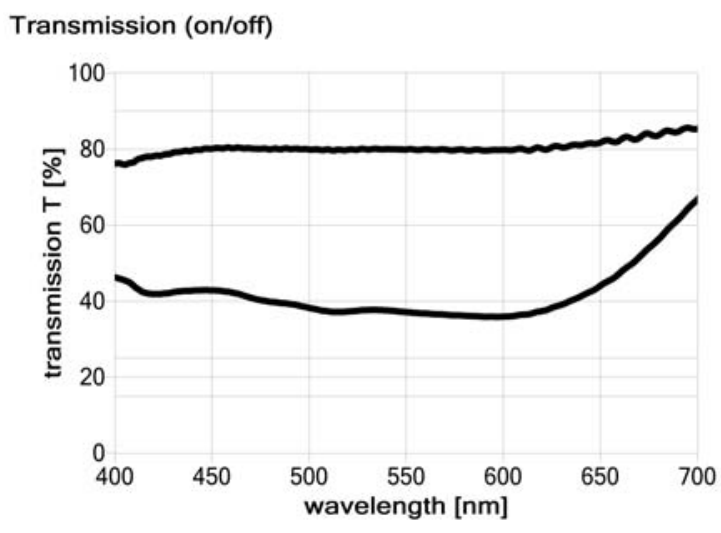

(a)

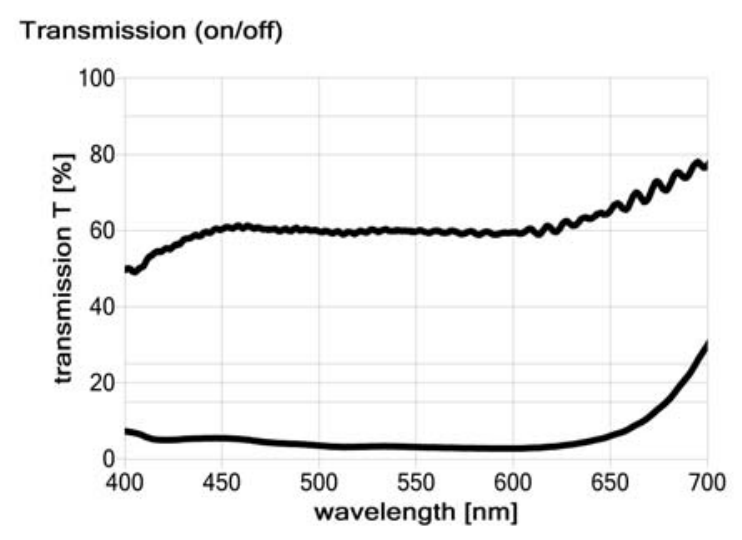

(b)

Figure 6. Simulated transmission curves for ALCW mixtures: (a) 80\% transmission in offstate, (b) 60\% transmission in off state 
As maximum absorption coefficients vary from one dye to another, it requires the use of different concentrations for the component dyes to achieve neutrally gray mixture. The OptiMix simulation program, by using data obtained from the characterization measurements, helps determine the dye composition of the mixture with desired total transmittance level and color (as given by coordinates on CIE1931 Chromaticity Diagram).

Since ALCWs are electrically switchable LC devices, we are working currently to improve our simulation software by including dynamic LC director relaxation and $4 \times 4$ matrix absorptive LC optics calculation to be capable of more precise prediction of the electro-optical characteristics of simulated DLC mixtures for devices on plastic substrates.

The simulated DLC composition data was used to prepare test mixtures for electro-optics and photostability testing by using the selected LC host and dichroic dyes synthesized in AMI's chemistry lab (Table 3). Figure 7 shows the measured transmission curves for visible spectral region for one of the prepared mixtures.

Table 3. DCNM-0310, DLC mixture composition (dye components only).

\begin{tabular}{|l|l|}
\hline DLC Component & Content, \% \\
\hline AMDD-Y-01123 & $0.74 \%$ \\
\hline AMDD-Y-01032 & $0.37 \%$ \\
\hline AMDD-Y-01089 & $0.37 \%$ \\
\hline AMDD-R-01303 & $0.27 \%$ \\
\hline AMDD-P-01254 & $0.52 \%$ \\
\hline AMDD-P-01112 & $0.44 \%$ \\
\hline AMDD-P-01215 & $0.44 \%$ \\
\hline
\end{tabular}

In addition, since solar spectrum consists of ultraviolet (UV), visible (VIS) and infrared (IR) parts, we are planning to expand our capability of electro-optics characterization setup by including spectral measurements in near infrared (NIR) wavelength range (up to $1000 \mathrm{~nm}$ ). This 
will allow characterization of the DLC mixtures and performance measurements for prototype devices on wider spectral range.

\section{TRANSMISSION (off-state - blue, on-state - red)}

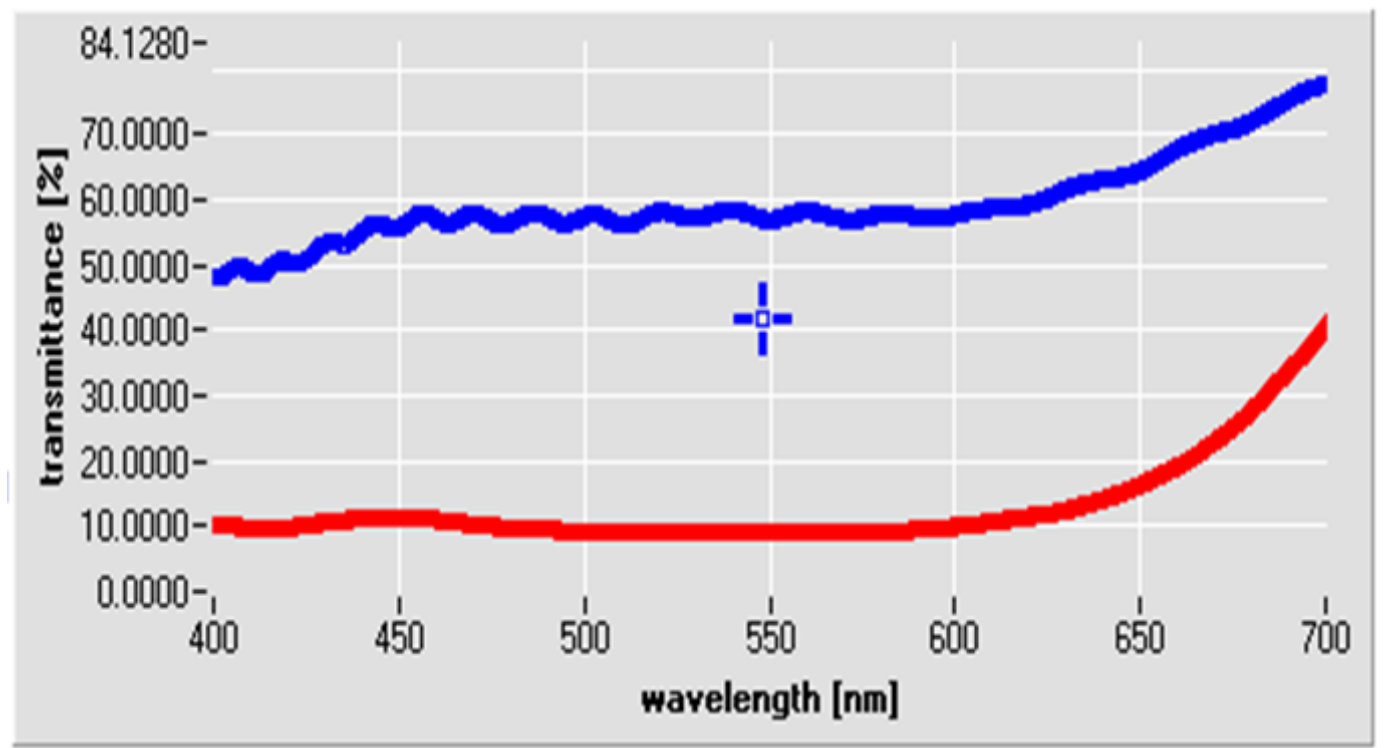

Figure 7. Measured transmission curves of a black e-Tint device.

Figure 8 show typical electro-optic curve of the device. It can be easily seen from the curve that on-switching time is less than $10 \mathrm{msec}$ and off-switching time is about $50 \mathrm{msec}$.

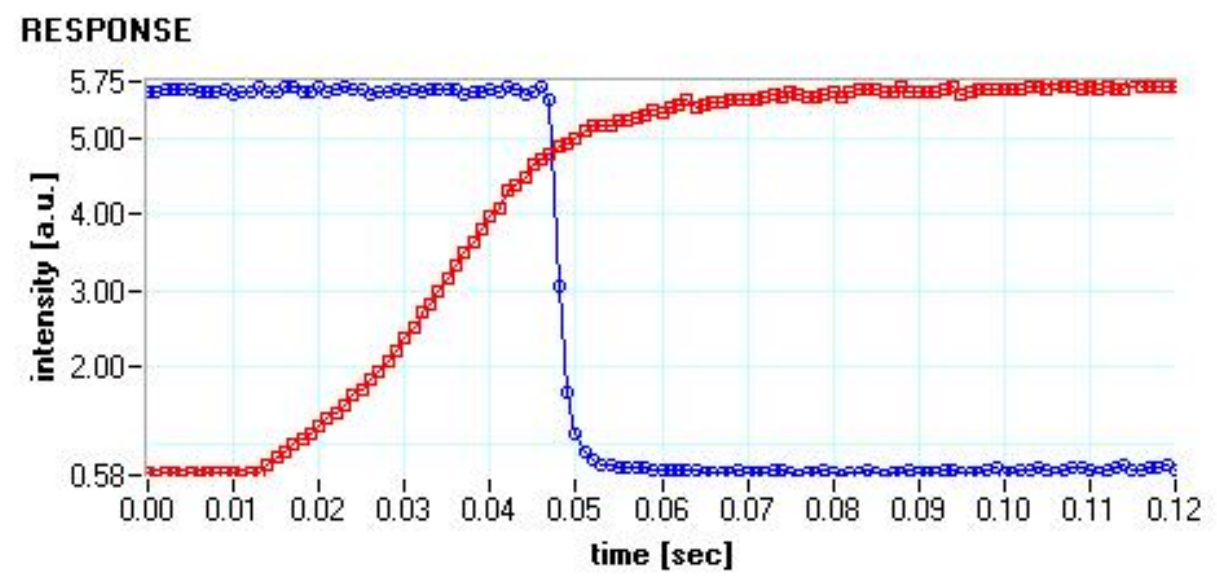

Figure 8. Typical electro-optic response curve for an e-Tint cell. Blue circles correspond to offon state change, red circles, to on-off change. 


\subsubsection{Substrates}

Figure 9 shows the cross section of the e-Tint ${ }^{\circledR}$ film proposed for ALCW panels. It consists of two 3 mil $(75 \mu \mathrm{m})$ thick plastic substrates coated with $\sim 100$-nm thick transparent ITO electrode with sheet resistance of $200 \Omega /$ square. Then a 100 -nm thick passivation layer is placed on top of the ITO to provide protection against shorts. Alignment layer determine the orientation of the liquid crystal in the absence of an applied field. In this case, the alignment layer will be a polyimide (PI) providing homeotropic alignment. Depending on the choice of the polyimide, the alignment layer can also serve as the passivation layer thereby eliminating the need for separate coating. The substrates are separated by $6-\mu \mathrm{m}$ plastic spacers.

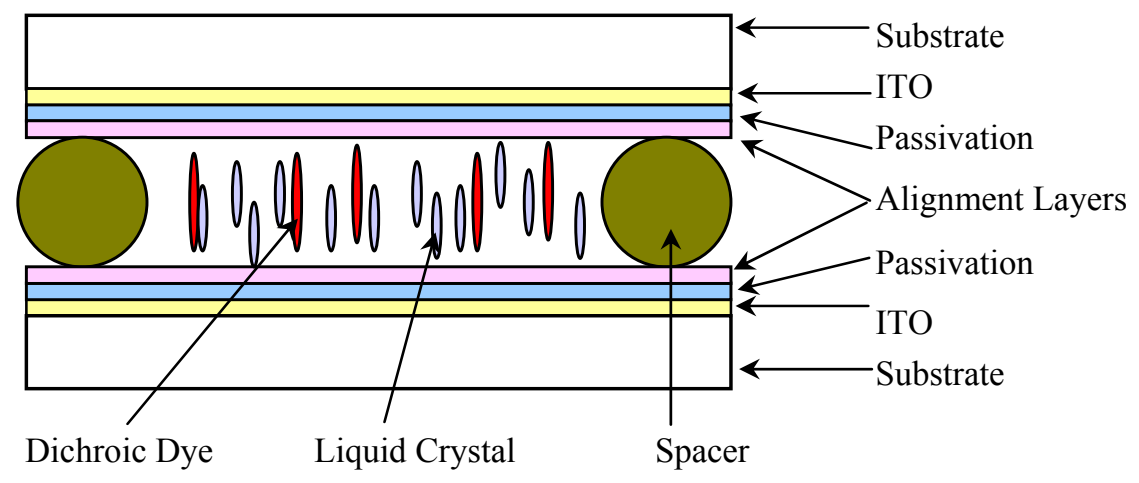

Figure 9. Diagram of an e-Tint ${ }^{\circledR}$ liquid crystal cell in the "voltage-off" or clear state. The guest-host liquid crystal mixture is represented by the rods at the center of the device.

There are several major differences between the proposed cell structure and a conventional LCD panel. Foremost, for Adaptive Windows, the substrates are thin plastic films whereas for commercial LCD products, they are rigid glass plates. Glass has several structural and optical properties which has made it the material of choice for all LCD panels. It has no optical birefringence and is chemically stable to most solvents. It can withstand high temperatures compatible with semiconductor processing. This allows the LCDs to incorporate transistors on glass thereby enabling active matrix driving. The rigidity of the glass substrate 
increase the ability to control the cell gap to the tight tolerances needed for a polarizer based optical device. This, coupled with the necessity for active matrix, outweigh the advantages of roll-to-roll processing and have forced the LCD industry to retain its batch processing methods. Although the size of substrates have increased dramatically in recent years, this approach is not viable for window applications. In addition to size limitations, the cost of the window panels should be taken into account.

Since e-Tint ${ }^{\circledR}$ is a guest-host system, it does not require an optically isotropic substrate. Furthermore, there is no need for polarizers for its operation. As such, the tolerances in cell gap can be dramatically increased. Finally, the window is not a display and does not require active or passive matrix driving electronics. The freedom from these constraints allows us to consider plastic as the substrate of choice. On the other hand, the required tolerances are still significantly more than those of a conventional web handling system. Furthermore, the system has to be compatible with liquid crystal manufacturing requirements, such as the need to operate in cleanroom environment.

A number of commercially available plastic films were considered as possible candidates as substrates for use in large-area ALCWs in regards to optical (optical transmittance of $90 \%$ or higher, low haze $[<1 \%]$, low or no birefringence, no color tint) and mechanical (good mechanical and thermal stability) requirements, and availability. Among those the following were tested: cyclic olefin copolymer (COC), polyethylene terephthalate (PET), polycarbonate (PC), and triacetate cellulose (TAC).

Table 4 lists some characteristics of the films under consideration.

Table 4. Comparison of physical and chemical characteristics for plastic films. 
ADAPTIVE LIQUID CRYSTAL WINDOWS: FINAL TECHNICAL REPORT

\begin{tabular}{|c|c|c|c|}
\hline Polymer & $\begin{array}{c}\text { Polyethylene } \\
\text { Terephthalate (PET) }\end{array}$ & Polycarbonate (PC) & $\begin{array}{c}\text { Triacetyl } \\
\text { Cellulose (TAC) }\end{array}$ \\
\hline Chemical Structure & & & \\
\hline Density & $\begin{array}{l}1.370 \mathrm{~g} / \mathrm{cm}^{3} \text { (amorphous) } \\
1.455 \mathrm{~g} / \mathrm{cm}^{3} \text { (crystalline) }\end{array}$ & $1.20-1.22 \mathrm{~g} / \mathrm{cm}^{3}$ & \\
\hline $\begin{array}{l}\text { Glass transition } \\
\text { temperature }\left(\mathrm{T}_{\mathrm{g}}\right)\end{array}$ & $75^{\circ} \mathrm{C}$ & $150^{\circ} \mathrm{C}$ & \\
\hline Melting point $\left(\mathrm{T}_{\mathrm{m}}\right)$ & $260^{\circ} \mathrm{C}$ & $267^{\circ} \mathrm{C}^{*}$ & \\
\hline Need for a hard coat & No & Yes & Yes \\
\hline ITO coated & Yes & No & No \\
\hline $\begin{array}{l}\text { Conductive polymer } \\
\text { coated }\end{array}$ & Yes & No & No \\
\hline $\begin{array}{l}\text { Minimum thickness } \\
\text { available }\end{array}$ & $\begin{array}{c}2-3 \mathrm{mil} \\
(50-75 \mu \mathrm{m})\end{array}$ & $\begin{array}{c}7 \mathrm{mil} \\
(175 \mu \mathrm{m})\end{array}$ & $\begin{array}{c}3 \mathrm{mil} \\
(75 \mu \mathrm{m})\end{array}$ \\
\hline
\end{tabular}

PET film has relatively good optical properties (transmittance of $\sim 90 \%$ ), but possess birefringence that can cause optical chromatic distortion of light propagation. The value of birefringence and its uniformity across the film depends on manufacturer and method they use in PET production.

PC and TAC films, despite their better optical performance (light transmission $>90-92 \%$, low haze, low or no birefringence), need additional layers or coatings to make them scratch resistant. In the case of using conductive polymer $(\mathrm{CP})$ as transparent electrode, there is also a need for chemical protection layer against solvents used in AlphaMicron's process of functional coating application. In addition, there is a scarce supply of ITO-coated PC films and no supply for ITO-coated TAC films, which limits the use of these films for large scale production of 
ALCW products. On the contrary, PET films are readily available and there is a number of ITO and a couple of conductive polymer coaters that work with PET on a regular basis.

Out of three films we have chosen PET as substrate for our project. First this film is available with conductive coatings. Further, while a CP-coated plastic film is potentially less expensive alternative to the ITO-coated film, we used the ITO-coated one due to our more extensive experience with this type of the film. To minimize the birefringence effect while not compromising our ability to handle film on the R2R machine, we used 3-mil (75- $\mu \mathrm{m})$ thick film.

As for other types of the films, we are currently working with web coaters to develop a hard coat that would provide scratch and chemical protection to PC and TAC films, as well as with ITO coaters to make ITO-coated PC and TAC films.

\subsubsection{Conductive Layer}

Since the ITO-coated plastic materials are contribute significantly to the cost of e-Tint ${ }^{\circledR}$ films, one of less expensive options pursued was PEDOT-based conductive polymer coating. Water-based conductive polymer solutions can be applied to PET, PC, or TAC films without requiring a $\mathrm{HC}$ for chemical protection of plastic. Conductive polymer coatings have good transparency in the visible region, good electrical conductivity, and environmental stability.

Table 5 list possibly candidates we considered for use in ALCW prototype cells, Table 5. ORGACON conductive coating formulations from Agfa-Gevaert N.V.

\begin{tabular}{|l|l|l|l|l|l|}
\hline Type & LBS3 & HBS3 & S103 & S203 & S303 \\
\hline $\mathrm{pH}, 20^{\circ} \mathrm{C}$ & $<2,5$ & $<2,5$ & $<2,5$ & $<2,5$ & $<2,5$ \\
\hline Viscosity cPs, $22^{\circ} \mathrm{C}$ & $<25$ & $<35$ & $<25$ & $<30$ & $<15$ \\
\hline \% PEDOT:PSS & 1.1 & 1.1 & 1.0 & 1.1 & 0.54 \\
\hline Coating, surfactant added & & & & & \\
\hline Wet thickness $[\mu \mathrm{m}]$ & 40 & 40 & 20 & 40 & 40 \\
\hline Drying time + temp & $3 / 130$ & $3 / 130$ & $3 / 130$ & $3 / 130$ & $3 / 130$ \\
\hline
\end{tabular}


ADAPTIVE LIQUID CRYSTAL WINDOWS: FINAL TECHNICAL REPORT

\begin{tabular}{|l|l|l|l|l|l|}
\hline \multicolumn{1}{|c|}{$[\mathrm{min}] /.\left[{ }^{\circ} \mathrm{C}\right]$} & & & & & \\
\hline $\begin{array}{l}\text { Surface resistance } \\
{[\mathrm{Ohm} / \mathrm{sq}]}\end{array}$ & $<200$ & $<200$ & $<300$ & $<200$ & $<300$ \\
\hline \%VLT without substrate & $>77$ & $>76$ & $>88$ & $>75$ & $>86$ \\
\hline comments: Type & coating & coating & $\begin{array}{l}\mu- \\
\text { gravure }\end{array}$ & $\begin{array}{l}\text { spin } \\
\text { coating }\end{array}$ & coating \\
\hline Additives & & $\begin{array}{l}\text { binder, } \\
\text { UV- } \\
\text { stabilizer }\end{array}$ & & \\
\hline & $\begin{array}{l}\text { surfactant } \\
\text { to be added }\end{array}$ & $\begin{array}{l}\text { surfactant } \\
\text { to be } \\
\text { added }\end{array}$ & $\begin{array}{l}\text { ready for } \\
\text { use }\end{array}$ & $\begin{array}{l}\text { ready } \\
\text { for use }\end{array}$ & $\begin{array}{l}\text { ready for } \\
\text { use }\end{array}$ \\
\hline
\end{tabular}

We concentrated on AGFA's Orgacon S103 and S303 conductive polymer materials as ones that produce more transparent (although more resistive) conductive layers. However, we found that S103 polymer coating interacts with dyes in e-Tint ${ }^{\circledR}$ mixtures at elevated temperatures $\left(>60^{\circ} \mathrm{C}\right)$, causing discoloration of the e-Tint ${ }^{\circledR}$ cells; therefore, we selected a new S303 material that does not interact with dye-doped liquid crystal mixtures at elevated temperatures.

For testing conductive polymer solutions applied to the roll of the plastic film, we used MiniLabo coating machine equipped with a hot air drier (Figure 10). 


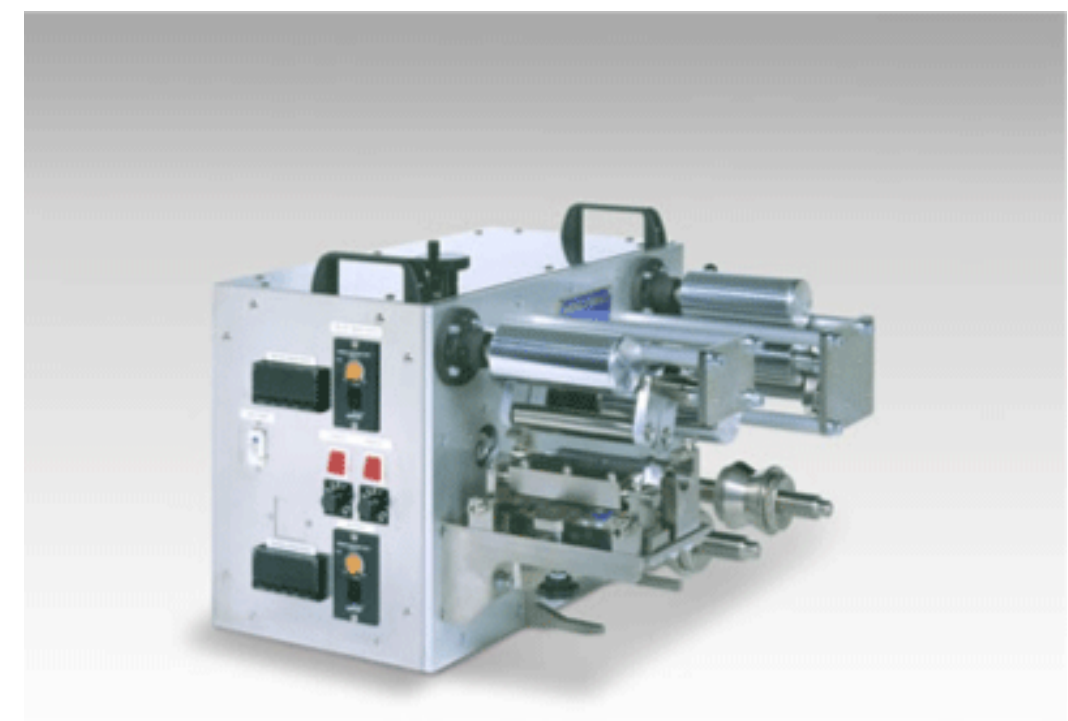

Figure 10. MiniLabo web coating machine from Yasui Seki, Japan, utilizing MICROGRAVURE coating method.

This machine allows application of various coatings to 5 in wide web of plastic film by MICROGRAVURE ${ }^{\mathrm{TM}}$ application method [17]. Figure 11 show a schematic diagram of the method.

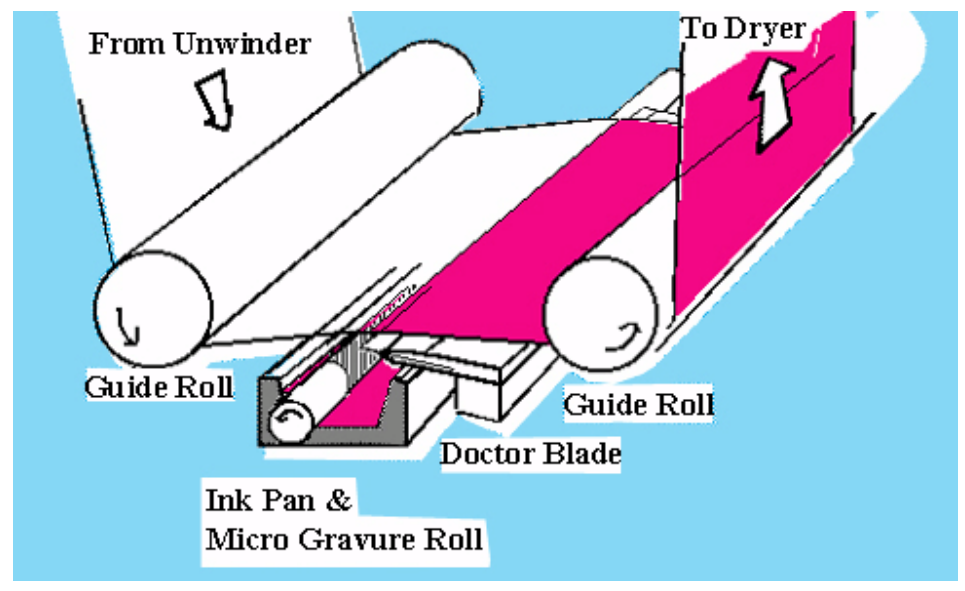

Figure 11. A schematic diagram demonstrating how the MICROGRAVURE ${ }^{\mathrm{TM}}$ application method works. 
We have achieved good results with PET film coated with AGFA'S S303 conductive polymer materials. Since ALCW devices are field driven, it allows reducing the thickness of the conductive polymer to achieve up to $1.0-1.5 \mathrm{kOhm} /$ square of surface resistivity. That will increase transmittance of CP-coated film. However, as mentioned in the previous section, the current e-Tint ${ }^{\circledR}$ cell manufacturing process with the TAC or PC requires having a protective $\mathrm{HC}$ barrier for solvents that are used in alignment material application.

\subsubsection{Sealing glue}

In order to define a shape of the active area of ALCW cells as well as to provide a tight containment to protect LC mixture from leaking and exposure to the environment, the cells needs a seal. The seal should be compatible with the cell manufacturing process and do not interfere with the LC layer functionality. In the roll-to-roll manufacturing process we use UV-curable glues. Before curing, the UV-curable glues usually are in a high viscosity liquid form that allows for easy application to the surface of the film by using a glue dispensing machine or by screen printing. The first method allows for glue application in complex curve shapes and can be easily reprogrammed. The second method is capable of almost instant coverage of large areas of the surface with glue. It is not as flexible as first method with respect to changing the pattern, but it is usually faster, capable of patterns of higher resolution, and therefore more preferable for large volume production runs.

We tested three different UC-curable adhesives (Table 6) to try in ALCW cell production. Loctite 3106 and Loctite 3107 are UV-curable adhesives form Henkel AG \& CO., KGaA, Dymax 3094 is from Dymax Corporation. Out of thee, Table 6. UV curable sealing glues

\begin{tabular}{|l|l|l|l|}
\hline Adhesive & Dymax 3094 & Loctite 3106 & Loctite 3107 \\
\hline
\end{tabular}


ADAPTIVE LIQUID CRYSTAL WINDOWS: FINAL TECHNICAL REPORT

\begin{tabular}{|l|l|l|l|}
\hline Hardness, durometer & D60 & D53 & D27 \\
\hline Adhesion force F [N], ITO & 0.23 & 0.83 & 1.75 \\
\hline Adhesion force F [N], ITO + alignment layer & 1.9 & 0.40 & 0.9 \\
\hline
\end{tabular}

Based on the results of the testing, we selected Dymax 3094 for manufacturing the test cells. Dymax 3094 provides stronger adhesion in between the plastic substrates coated with functional alignment layers. When the cells are assembled, the seal glue can be cured by exposure to UV and/or visible light of sufficient intensity. The speed of cure depends upon the UV intensity and spectral distribution of the light source, the exposure time, and the light transmittance of the substrates. In addition, this adhesive has minimum interaction with DLC mixture prior to curing and does not interact with the mixture after it is cured.

\subsection{Manufacturing e-Tint ${ }^{\circledR}$ Film}

AlphaMicron has demonstrated its e-Tint ${ }^{\circledR}$ technology on plastic films for eyewear applications. It is based on a batch processing method using 14 in $\times 14$ in substrate size can serve the needs of the market. For window application the width of starts at 36 in and the length can dramatically vary from 48in to $72 \mathrm{in}$. Therefore, the only viable method for production of a film must be roll-to-roll. While each step has been demonstrated using the 14in wide substrates, rollto-roll equipment must be utilized and tested for large scale production.

Figure 12 shows the schematic of the proposed system. It is based on a roll-to-roll (R2R) approach where some portion of the process can be performed independently. A 48in wide roll of PET film is unwound, coated with thin film of polyimide using a MICROGRAVURE coating method, pre-cured to evaporate the solvents, and rewound. The roll is then placed in a curing oven to complete the polyimide curing process. After completion, it is removed for the assembling process. 


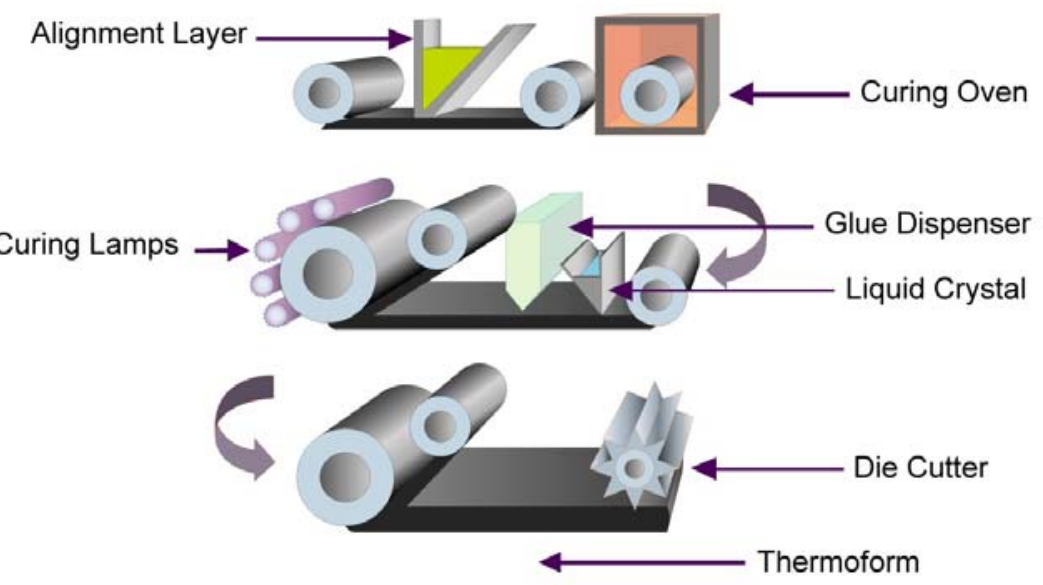

Figure 12. Manufacturing process flow for e-Tint ${ }^{\circledR}$ ALCW technology.

Here, the film is unwound and coated with a thin layer of liquid crystal material. UV curable glue is dispensed on the plastic in the shape of the final window. A second polyimide coated substrate is laminated and the assembly is light cured and wound up. As a final step, the reel is placed on a web that unwinds, laminates the liquid crystal film to other films if necessary and die cuts the laminated assembly.

To fabricate $1 \mathrm{ft} \times 1 \mathrm{ft}$ e-Tint ${ }^{\mathrm{A}}$ ALCW tiles, we used 3-mill thick ITO-coated PET film on a roll. Several 14in wide rolls of the film were web coated with the alignment layer. Two rolls of the prepared film were placed on AMI's new R2R machine. The test tiles were produced on the R2R machine by dispensing a layer of DCNM-0310 dichroic liquid crystal and by screen printing the Dymax 9034 sealing glue in a $1 \mathrm{ft} \times 1 \mathrm{ft}$ square pattern on one of the substrates followed by lamination of the second substrate, UV curing the glue, and cutting the film into sheets (Figure 13).

The process of manufacturing on AlphaMicron's custom roll-to-roll (R2R) equipment requires further optimization to achieve high degree reproducibility of LC layer uniformity in 
ALCW tiles and its performance. During the manufacturing we encountered some problems related to UV glue deposition consistency, air trapping in the LC layer, and development of voids in cells after the manufacturing process is completed. These problems were resolved by optimizing manufacturing process parameters.

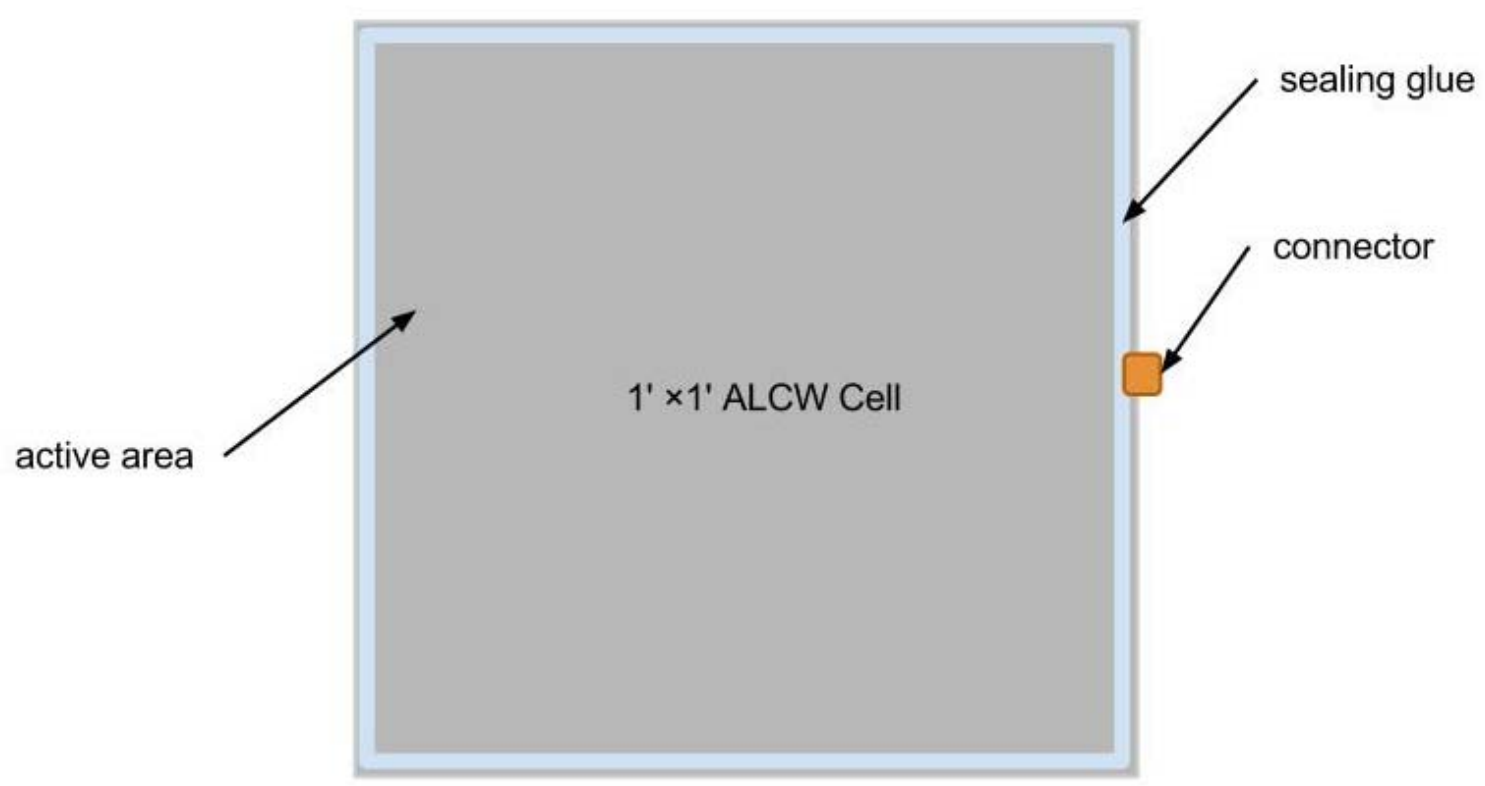

Figure 13. A schematic representation of an ALCW cell.

In order to achieve a consistent and controlled glue deposition by using a screen printer on the R2R machine, we have tried screen meshes with various mesh opening ratios. We have found that meshes with 460 openings per inch $(180$ per $\mathrm{cm})$ work the best for our R2R machine. The amount of the deposited glue can be controlled further by the angle and pressure of the screen printer squeegee.

The air trapping has been partially resolved by maintaining a continuous LC layer before the lamination rollers on $\mathrm{R} 2 \mathrm{R}$ machine.

Further to resolve the void formation in produced cell, we separated the variable parameters of the R2R machine that control the glue dragging and degassing of the LC mixture 
in the active area of ALCW cells. We have found that by controlling the pressure of the lamination rollers we can achieve consistency in avoiding LC degassing.

When the lamination pressure is too high, the active area of the cells is overpressed causing the substrates to sag in between the spacers during the lamination. This leads to excessive pushing out the LC mixture, reducing its volume in the active area. After the lamination is done, the spacers push the substrates back, but since the amount of LC mixture, contained in the cell by the sealing glue, is insufficient, it creates a negative pressure inside the cells. After a period of time, hours or days, depending on the degree of overpressing, this negative pressure causes degassing of the liquid crystal mixture and, possibly, air diffusion through the substrates of the cells, resulting in creation of gas bubbles that become irreversible defects. Air diffusion through the cell substrates requires further studying.

When the lamination pressure is too low, it leads to excessive amount of the easily moving LC in the cells that can cause appearance of darker thick spots, areas with local increase of cell gap under gravity.

We continued optimization of the manufacturing ALCW cells by varying the hardness of the lamination rollers. We have found that softer surface of the rollers (rubber of durometer 40A) allows application of the more uniform pressing the LC cell during the lamination due to increased area of contact, but it requires an increased pressure to flatten more viscous line of the sealing glue. Such increase pressure on the glue lines can easily lead to overpressing the LC cell.

The lamination rollers with hard surfaces could potentially take care of the glue lines during the lamination without overpressing the cells. For that purpose, two metal rollers with polished surfaces would do the job. However, due to imperfections of the roller surfaces, as well 
as thickness variations of the plastic films, lamination rollers with moderate surface softness (60A durometer) are more suitable for the optimized lamination process.

The process of manufacturing on AlphaMicron's custom roll-to-roll (R2R) equipment requires further optimization to achieve high degree reproducibility of LC layer uniformity in ALCW tiles and its performance.

\subsection{Testing of ALCW Tiles}

\subsubsection{Electro-optic and dielectric characterization}

To drive several $1 \mathrm{ft} \times 1 \mathrm{ft}$ e-Tint ${ }^{\circledR}$ ALCW tiles fabricated as described above, we used flexible contact connectors coated with conductive pressure sensitive adhesive (PSA). To activate the cells we applied a low voltage, $6-10 \mathrm{~V}$, square pulse AC signal. By using some of the fabricated ALCW tiles, small switchable window demos were made for internal testing (Figure 14). The window is driven either with a small battery embedded in the window frame or with a small solar cell mounted on the top portion of the frame. Now, we are preparing for manufacturing a large test window demo for testing ALCWs in a building structure.

The measurement were performed by using a setup comprising of an Agilent 4284A Precision LCR Meter with Option 001 connected through GPIB interface to a host computer. Data (impedance and phase of impedance of the panel as a function of driving signal frequency from $20 \mathrm{~Hz}$ to $1 \mathrm{MHz}$ ) at various driving voltages $(0.1-9 \mathrm{~V})$ were collected by using AMI's custom Material Characterization Program installed on the host computer. The collected data were stored in a file for further processing using SigmaPlot graphing software. Below are several representations of the data. 

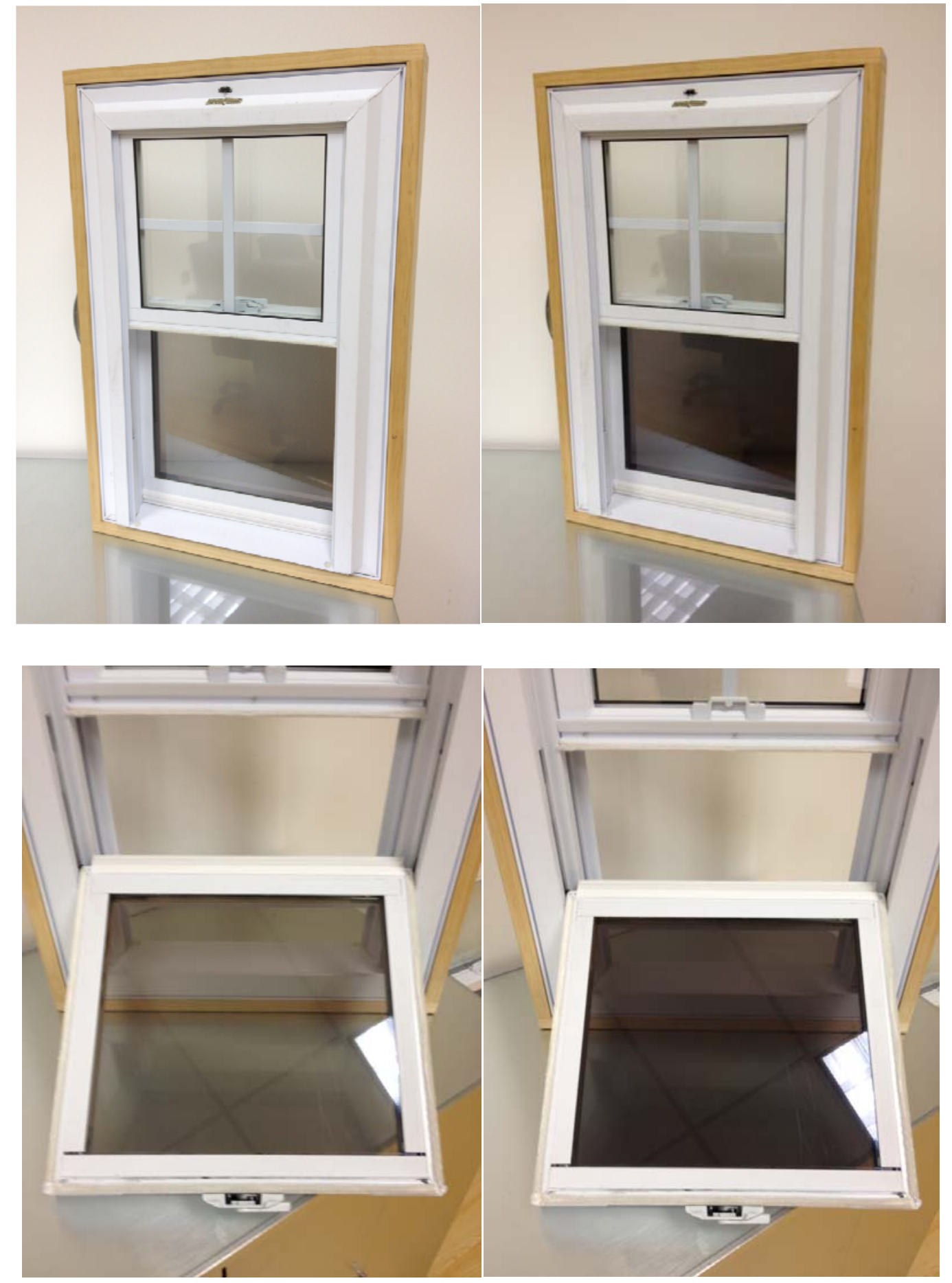

Figure 14. A demo window made with $1 f t \times 1 f t$ ALCW film laminated to the glass surface of the bottom panel. The window is driven either with a small battery embedded in the window frame or with a small solar cell mounted on the top portion of the frame. 


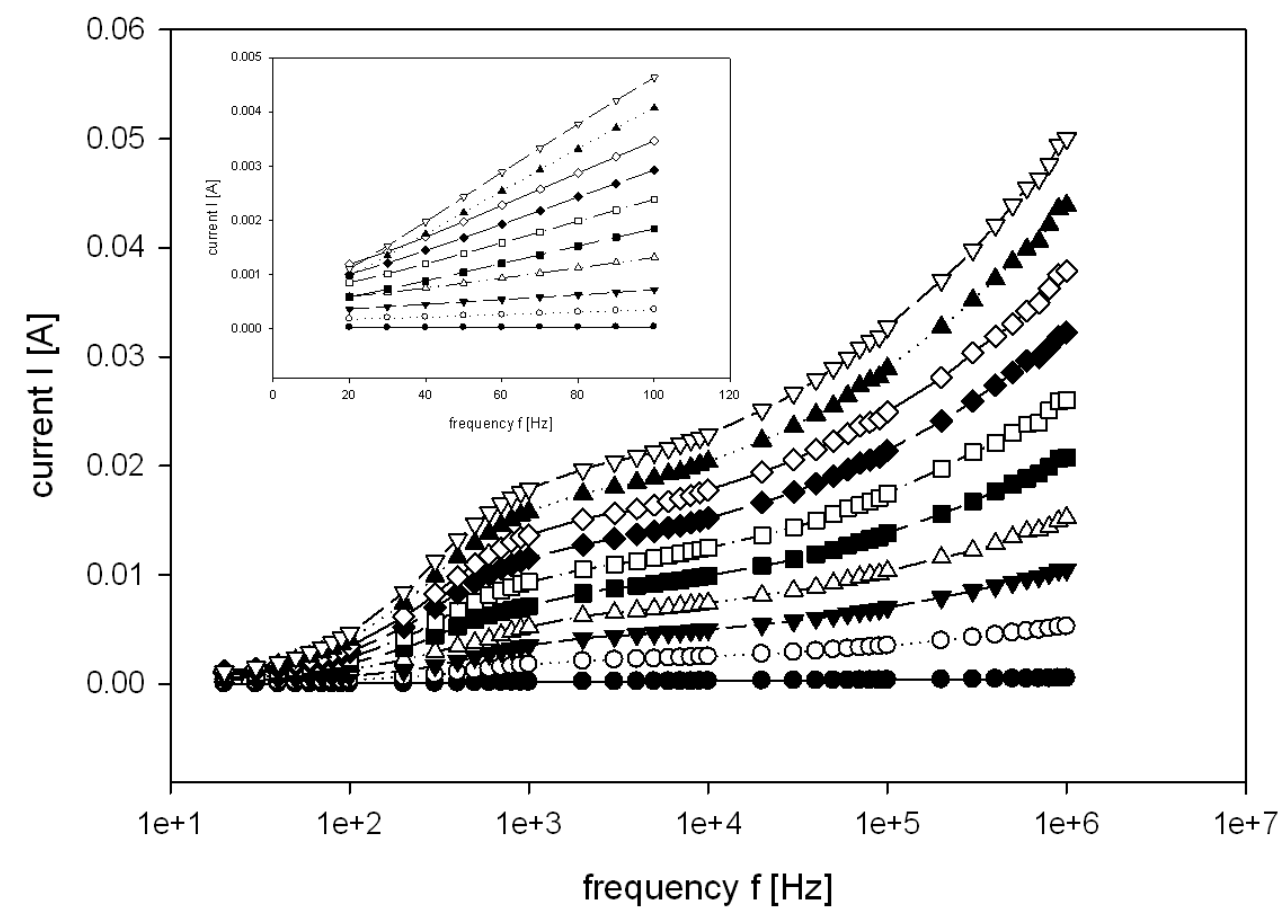

Figure 15. Current as function of driving AC signal frequency in a $1 \mathrm{ft} \times 1 \mathrm{ft}$ ALCW cell. Applied voltage is fixed for each curve and increases from the bottom curve (0.1V) to the top one (9V).

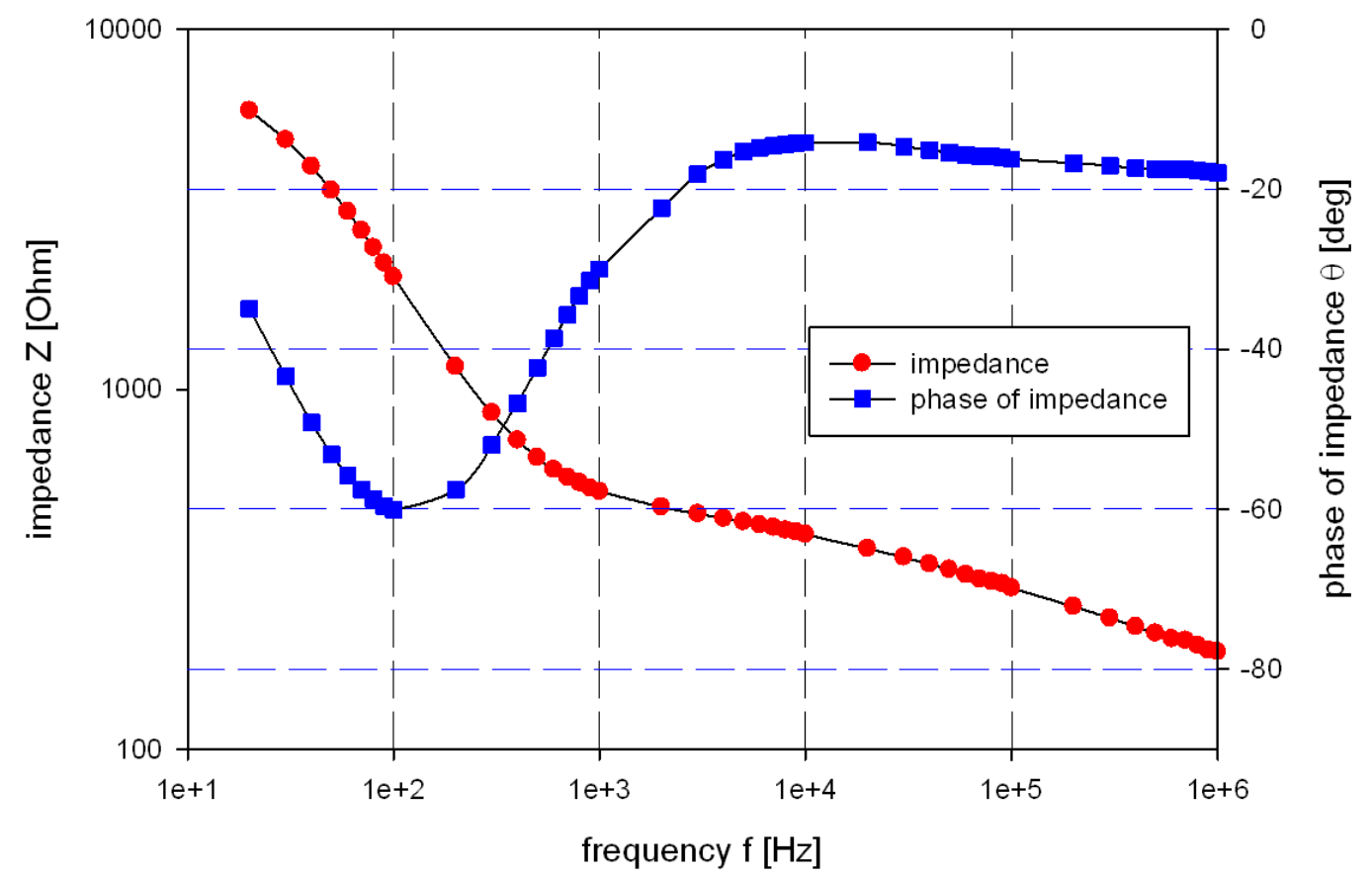

Figure 16. Impedance and phase of impedance measurements for a $1 \mathrm{ft} \times 1 \mathrm{ft} A L C W$ panel. Applied voltage is fixed at $6 \mathrm{~V}$. 
ADAPTIVE LIQUID CRYSTAL WINDOWS: FINAL TECHNICAL REPORT

At $60 \mathrm{~Hz}$ and $6 \mathrm{~V}$, the true power consumption of the $1 \mathrm{ft} \times 1 \mathrm{ft}$ panel is about $6.2 \mathrm{~mW}$ (or $6.7 \mu \mathrm{W} / \mathrm{cm}^{2}$ ). If linear dependence of power consumption on the area of the window panel is assumed, a $3 \mathrm{ft} \times 5 \mathrm{ft}$ window panel would require $\sim 100 \mathrm{~mW}$ of power in ON-state.

\subsubsection{Visible Transmission and SHGC}

Three thing happen to solar radiation as it passes through a film. Some of it transmitted, some reflected, and the rest is absorbed. These are three components of solar that determine many of the other energy performance of the film, such as the solar heat gain coefficient and shading.

Visible light is a small portion of the electromagnetic spectrum. The visible transmittance (VT) is an optical property that indicates the amount of visible light transmitted. The NFRC's VT is a whole window rating and includes the impact of the frame which does not transmit any visible light. While VT theoretically varies between 0 and 1, most values among double- and triple-pane windows are between 0.30 and 0.70 . The higher the VT, the more light is transmitted. A high VT is desirable to maximize daylight.

The SHGC is the fraction of incident solar radiation admitted through a window, both transmitted directly and absorbed and subsequently released inward. SHGC is expressed as a number between 0 and 1 . The lower a window's solar heat gain coefficient, the less solar heat it transmits.

$$
S H G C=T_{S}+N_{t} A_{S}
$$

where $T_{S}$ is solar radiation transmitted through the window, $A_{S}$ is solar radiation absorbed by the window, and $N_{t}$ is inward heat transfer facto.

The nationally recognized rating method by the National Fenestration Rating Council (NFRC) is for the whole window, including the effects of the frame [18]. Alternately, the center- 
of-glass SHGC is sometimes referenced, which describes the effect of the glazing alone. Whole window SHGC is lower than glass-only SHGC, and is generally below 0.8 .

We are planning to use Window Simulation Software Program from Lawrence Berkeley National Laboratory to help with analyzing thermal and optical performance of ALCWs.

\subsubsection{Environmental testing}

Due to space limitation in the testing chambers, we prepared smaller, 2 in $\times 2$ in test cells for UV stability and lifetime testing. The test cells were prepared by using the same DLC mixtures and the same R2R assembly method. The test cells with DLC mixtures are currently were tested for photochemical stability of DLC mixtures in ALCWs with respect to UV and visible solar radiation.

Originally as a photostability test equipment, we planned to use our QUV Accelerated Weathering Tester with Solar Eye UV Irradiation Controller (model QUV-SE) (Figure 17) and Q-SUN Xenon Test Chamber (model QSUN Xe-3-B) (Figure 18) both from Q-Lab Corporation. This equipment is capable of reproducing sunlight damage that may occur over months or even years outdoors.

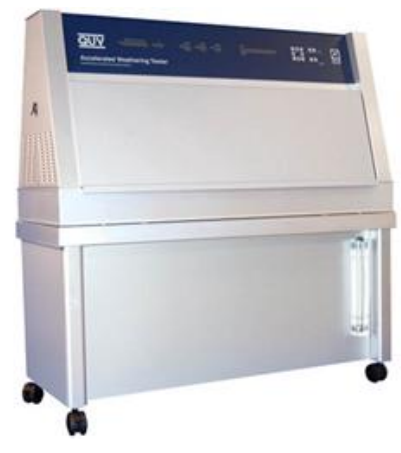

Figure 17. QUV Accelerated Weathering Tester. 


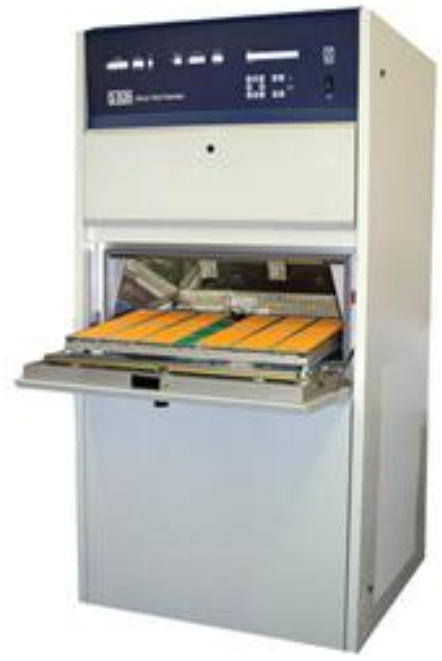

Figure 18. Q-SUN Xe-3 Xenon Test Chamber.

Ultraviolet light causes almost all the photodegradation to materials exposed outdoors. The QUV tester reproduces only the UV portion of the spectrum. QUV's UVA-340 lamp is an excellent simulation of short-wave sunlight.

Eventually we limited our photostability testing to the Q-Sun Xenon Test Chamber that reproduces the damaging wavelengths of light encountered either indoors or outdoors. Xenon lamps emit ultraviolet, visible and infrared light. Filtered xenon arc lamps are the best way to test sensitivity of our ALCWs to the longer UV wavelengths and visible wavelengths of sunlight.

The test procedures include testing photostability of small $(2$ in $\times 2$ in $)$ ALCW samples in deactivated (off) state. Although the behavior of dyes in isotropic aqueous and organic solvents and in polymeric and textile substrates is well documented, there have not been many studies on dichroic dye fading in liquid crystalline media, especially for switchable attenuation devices for outdoor use. To improve the life time of the AMLW cells, we tried several UB block films laminated to the test cells. The cells themselves were laminated to mirror glasses. 
The test cells, half covered with UV blocking films were placed in Q-Sun Xenon Test Chamber with light intensity set at $55 \mathrm{~W} / \mathrm{m}^{2}$ for normal incidence. The cells were periodically checked for color changes. The test results are presented below, in Table 7.

Table 7.Results of the UV stability testing of ALCWtest cells with UV blocks

\begin{tabular}{|c|c|c|c|c|c|c|}
\hline $\begin{array}{l}\text { UV Block } \\
\text { Name }\end{array}$ & Configuration & $\begin{array}{l}144 \mathrm{~h} / \\
300 \mathrm{~kJ}\end{array}$ & $\begin{array}{l}288 \mathrm{~h} / \\
600 \mathrm{~kJ}\end{array}$ & $\begin{array}{l}432 \mathrm{~h} / \\
900 \mathrm{Kj}\end{array}$ & $\begin{array}{l}576 \mathrm{~h} / \\
1200 \mathrm{~kJ}\end{array}$ & $\begin{array}{l}720 \mathrm{~h} / \\
1500 \mathrm{~kJ}\end{array}$ \\
\hline PSA A & TAC/PSA-A & Good & Good & Good & Good & Good \\
\hline PSA B & TAC/PSA-B & Good & Good & Good & Good & Good \\
\hline $\begin{array}{l}\text { M1 } \\
082409\end{array}$ & UVHC /PET / A & Moderate & $\mathrm{Bad}$ & $\mathrm{Bad}$ & $\mathrm{Bad}$ & $\mathrm{Bad}$ \\
\hline $\begin{array}{l}\text { SP UV } \\
\text { Stab }\end{array}$ & $\begin{array}{l}\text { UVHC /PC / } \\
\text { UVHC/PSA }\end{array}$ & $\mathrm{Bad}$ & $\mathrm{Bad}$ & $\mathrm{Bad}$ & $\mathrm{Bad}$ & $\mathrm{Bad}$ \\
\hline UV01 PC & $\begin{array}{l}\text { UVHC / PET / } \\
\text { UVHC/PSA }\end{array}$ & $\mathrm{Bad}$ & $\mathrm{Bad}$ & $\mathrm{Bad}$ & $\mathrm{Bad}$ & $\mathrm{Bad}$ \\
\hline UV01S2 & UVHC / PET / A & Moderate & Bad & Bad & $\mathrm{Bad}$ & Bad \\
\hline $\begin{array}{l}\text { UVOM } \\
100 \mathrm{~V}-187\end{array}$ & UVHC / PET / A & Good & Good & Good & Good & Good \\
\hline $\begin{array}{l}\text { UV01S } \\
\text { (KDI) }\end{array}$ & UVHC / PET / A & Good & Good & Good & Good & Good \\
\hline ProTeck & UVHC / PET/PSA & Good & Good & Good & Good & Good \\
\hline HP92W & UVHC/PC/PSA & Good & Moderate & Moderate & $\mathrm{Bad}$ & $\mathrm{Bad}$ \\
\hline $\begin{array}{l}\text { U1006T- } \\
125\end{array}$ & UVHC/PET/PSA & $\mathrm{Bad}$ & $\mathrm{Bad}$ & $\mathrm{Bad}$ & $\mathrm{Bad}$ & $\mathrm{Bad}$ \\
\hline G01S -ITO & UVHC/PET/ITO/PSA & $\mathrm{Bad}$ & Bad & $\mathrm{Bad}$ & $\mathrm{Bad}$ & $\mathrm{Bad}$ \\
\hline
\end{tabular}

Note. UVHC - UV hard coat, A- adhesive, TAC - triacetyl cellulose film, PET -

polyethylene terephthalate film, PC - polycarbonate film, ITO - indium tin oxide layer, PSA 3M 8142K layer.

Good rating was given to the cells that did not show any visible changes at the time of checking. The Moderate rating were for minimal visible color changes observed in cells, and Bad 
rating were for the cells with definite severe visible changes observed in the cells after light exposure in Q-Sun Xenon Test Chamber. As such, we identified a number of UV blocking film configurations that allowed the cells withstand the light exposure for more than 720 hours. All the configurations are made with thin flexible film that do not affect much the flexibility of the base e-Tint film.

In addition to the photostability tests, we conducted thermo shock tests on 2 in $\times 2$ in cells in a thermoshock chamber. The chamber was set for cycling from $-40^{\circ} \mathrm{C}$ to $+85^{\circ} \mathrm{C}$ and back. The cells were kept at each extreme temperature for $30 \mathrm{~min}$. After 1000 cycles the cells showed only minor discoloration (Figure 19), while remaining fully functional.

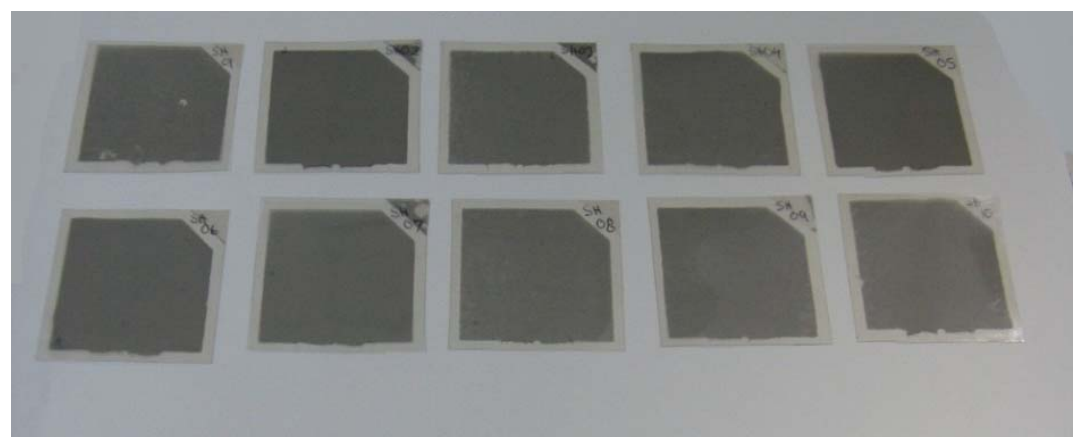

(a)

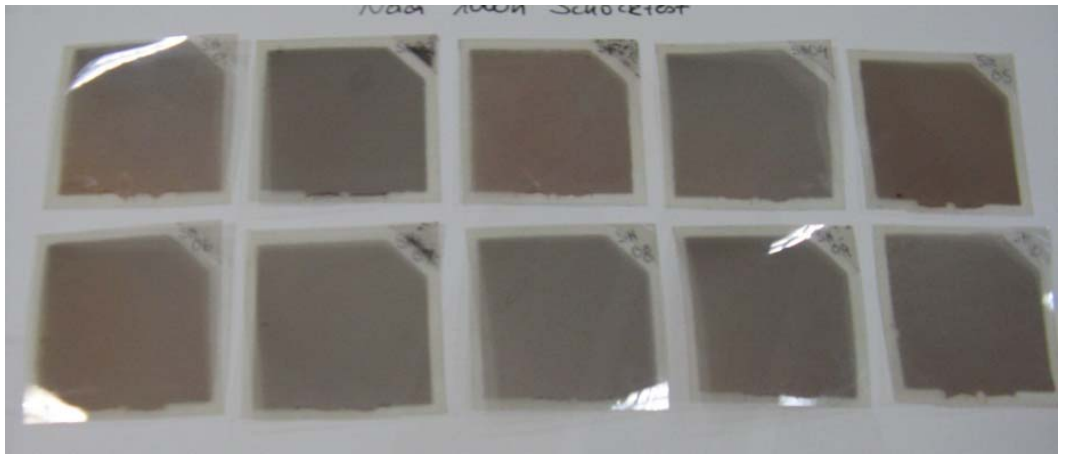

(b)

Figure 19. 2in $\times$ 2in test samples (a) before and (b) after 1000 hours of thermo shock testing. 
As e-Tint films are intended for lamination to regular windows, most likely on inside surface of a window panel (for aftermarket applications) or in between panels (for OEM applications), By doing so, we would reduce greatly exposure of the e-tint film to the environment (UV/VIS light and/or temperature); therefore, the current test result indicate possibility of achieving an extended lifetime by ALCWs necessary for commercial applications. A correlation between the test chamber results and lifetime of the panels needs further studies.

\subsection{Cost of production}

We calculated the cost of materials used in manufacturing $1 \mathrm{ft} \times 1 \mathrm{ft}$ test cells for ALCWs. The main components we considered for cost evaluation were DLC mixture, plastic substrates, and sealing glue. The cost of DLC mixture consist of the LC cost obtained commercially and cost of the dichroic dies produced in-house. The relatively high cost of these two ingredients is determined by low volumes of purchasing (LC) or producing (dichroic dies). With a mass production of the film, we expect this cost decrease by, at least, factor of 2 . The same expectation is for plastic substrates. In addition at this time about $30 \%$ of the film is lost in production. For larger panel production that number will be significantly lower (1-2\%). Table 8. Current cost of materials used in production of $1 \mathrm{ft} \times 1 \mathrm{ft}$ ALCW test cells

\begin{tabular}{|l|c|c|c|c|}
\hline \multicolumn{1}{|c|}{ Material } & Cost/unit & Units & Units $/ \mathrm{ft}^{2}$ & Cost per $\mathrm{ft}^{2}$ of film \\
\hline DLC & $\$ 16.74$ & $\mathrm{~g}$ & 0.55 & $\$ 9.21$ \\
\hline Plastic substrates & $\$ 1.74$ & sq. $\mathrm{ft}$ & 2.56 & $\$ 4.38$ \\
\hline Glue & $\$ 189.85$ & 1 & 0.0003 & $\$ 0.06$ \\
\hline Total & & & & $\$ 13.65$ \\
\hline
\end{tabular}


ADAPTIVE LIQUID CRYSTAL WINDOWS: FINAL TECHNICAL REPORT

In order to reduce cost of the materials, in particular associated with dichroic dye components, we have started to look for sources of less expensive materials for production ALCW windows, including starting materials for in-house synthesis of dichroic dyes.

\subsection{Adaptive windows technology network}

During working on the project, AlphaMicron, Inc. developed a strong network concerning adaptive windows technology. Dr. Bahman Taheri has communicated with Marc LaFrance (DOE), who emphasized the importance of environmental testing for glazing applications and provided us a copy of testing procedure for electrochromic windows. In addition, plans are made to meet with representatives from Lawrence Berkeley National Lab (LBNL) about their testing possibilities.

We expanded our adaptive windows technology further by becoming industrial partners with Prof. Ivan I. Smalyukh from Department of Physics and Department of Electrical, Computer, \& Energy Engineering, Founding Fellow at Renewable and Sustainable Energy Institute (RASEI), and Senior Investigator at Liquid Crystal Materials Research Center (LCMRC) of University of Colorado at Boulder. As a University professor, he and his Ph.D. students developed genuine interest and very strong excitement about adaptive windows technology.

As a founding fellow of the Renewable and Sustainable Energy Institute, a joint institute of NREL and the University of Colorado, Prof. Smalyukh interacts and closely collaborates with many researchers at NREL (Jao van de Lagemaat, Anne Dillon, Martha Symko-Davies, Garry Rumbles, Jeff Blackburn, Robert Tenent, Bryan Gregg, and many others). He also has access to the state-of the art facilities of Process Development and Integration Laboratory at NREL to help with testing and further development of the liquid crystal adaptive windows. 
ADAPTIVE LIQUID CRYSTAL WINDOWS: FINAL TECHNICAL REPORT

\section{Conclusions}

AlphaMicron's e-Tint ${ }^{\circledR}$ technology implemented on flexible plastic substrates meets all requirements for adaptive windows and has the following important features which make it suitable for the successful implementation:

1. Offers electronic controllable of variable transmittance in the range of $70 \%-30 \%$. This has been demonstrated in eyewear and light shutter products that are now commercially available.

2. Has been demonstrated on flexible plastic substrates. AlphaMicron manufactures its film and has commercialized an electronic eyewear based on 3 mil plastic substrates.

3. Provide a fail-to-clear option. In the case of power control failure, the film automatically switches to its clear state, providing unobstructed view.

4. Requires $\sim 100 \mu \mathrm{W} / \mathrm{cm}^{2}$ for operation. VALiD technology has very low power consumption. This enables operation with minimal power and as such can be energized with a small area solar cell.

5. Has excellent optical properties. Current commercial products have demonstrated class 1 optics. The uniformity in the color and lack of haze are essential in window applications.

6. Has proven record for durability. The technologies are now used in autodimming mirrors, eyewear, and light shutter applications.

7. Low cost transparent conductors. Since liquid crystals are voltage driven, high conductivity of the system is not required. Therefore, low cost solutions to transparent electrodes can be utilized. This option is not available for current driven systems like electrochromics. 
ADAPTIVE LIQUID CRYSTAL WINDOWS: FINAL TECHNICAL REPORT

\section{References}

1. U.S. Energy Flow. Lawrence Livermore National Laboratory. flowcharts.1lnl.gov.

2. Annual Energy Review 2010. U.S. Energy Information Administration. www.eia.gov.

3. J. Apte, D. Arasteh, Y. J. Huang. "Future Advanced Windows for Zero-Energy Homes.” ASHRAE Transactions, v. 109, 2003.

4. P. Monk, R. Mortimer, D. Rosseinsky, "Electrochromism and Electrochormic Devices" Cambridge University Press, 2007.

5. R. Vergaz, J. M. S. Pena, D. Barrios, I. Pérez and J. C. Torres. Electrooptical behaviour and control of a suspended particle device. Opto-Electronics Review, 15(3), 154-158 (2007).

6. Thermotropic Window Structures. 7817328 U.S. Patent 7,817,328; Filed September 4, 2007.

7. Transparent thermal insulating system, U.S. Patent 3,953,110; Filed May 20, 1974.

8. J.W. Doane, G. Chidichimo, N.A.P. Vaz, U.S. Patent 4,688,900.

9. P. Drzaic, Liquid Crystal Dispersions, World Science Publishing Co., Singapore (1995).

10. B. Taheri, P. Palffy-Muhoray, T. Kosa, D. L. Post "Technology for Electrically Varying Helmet Visor Tint” Proc. SPIE 4021, 114-119 (2000).

11. P. Oswald and P. Pieranski. Nematic and Cholesteric Liquid Crystals. Tailor \& Francis, 2005.

12. B. Bahadur, Liquid Crystals: Applications and Uses, World Science Publishing Co., 1991. 
13. F. Gharadjedaghi, Swiss Patent Application 1272/78, Feb 1978.

14. H. Zollinger, “Color Chemistry”, VCH, Weinheim (1991), pp. 375-9.

15. D. R. Waring, G. Hallas, "The Chemistry and Application of Dyes", Plenum Press, New York (1990).

16. H. Iwanaga, K. Naito, "Highly Soluble Antraquinone Dyes with $\mathrm{CF}_{3}$-Groups for GuestHost Liquid Crystal Displays”, Jpn. J. Appl. Phys., 37, L356 (1998).

17. A. V. Ivashchenko, "Dichroic Dyes for Liquid Crystal Displays”, CRC Press, Boca Raton, 1994.

18. The Yasui Seiki "Micro Gravure ${ }^{T M "}$ Coating Method. http://www.yasui.com/2004/ MicroGravure.pdf

19. NFRC 200-2010[E1A4]: Procedure for Determining Fenestration Product Solar Heat Gain Coefficient and Visible Transmittance at Normal Incidence. National Fenestration Rating Council: Greenbelt, MD; 2010. www.nfrc.org.

20. NFRC 201-2010[E0A2]: Procedure for Interim Standard Method for Measuring the Solar Heat Gain Coefficient of Fenestration Systems using Calorimetry Hot Box Methods. National Fenestration Rating Council: Greenbelt, MD; 2010. www.nfrc.org. 